University of Nebraska - Lincoln

DigitalCommons@University of Nebraska - Lincoln

Center for Brain, Biology and Behavior: Papers \& Publications

Brain, Biology and Behavior, Center for

9-27-2017

Brain encoding of saltatory velocity through a pulsed pneumotactile array in the lower face

Rebecca Custead

Hyuntaek Oh

Yingying Wang

Steven M. Barlow

Follow this and additional works at: https://digitalcommons.unl.edu/cbbbpapers

Part of the Behavior and Behavior Mechanisms Commons, Nervous System Commons, Other Analytical, Diagnostic and Therapeutic Techniques and Equipment Commons, Other Neuroscience and Neurobiology Commons, Other Psychiatry and Psychology Commons, Rehabilitation and Therapy Commons, and the Sports Sciences Commons

This Article is brought to you for free and open access by the Brain, Biology and Behavior, Center for at DigitalCommons@University of Nebraska - Lincoln. It has been accepted for inclusion in Center for Brain, Biology and Behavior: Papers \& Publications by an authorized administrator of DigitalCommons@University of Nebraska - Lincoln. 


\title{
Brain encoding of saltatory velocity through a pulsed pneumotactile array in the lower face
}

\author{
Rebecca Custead, ${ }^{1}$ Hyuntaek Oh, ${ }^{2}$ \\ Yingying Wang, ${ }^{3}$ and Steven Barlow ${ }^{4}$
}

1 Special Education and Communication Disorders, University of NebraskaLincoln, Lincoln, NE, USA; Center for Brain, Biology and Behavior, University of Nebraska-Lincoln, Lincoln, NE, USA. email rcustead@huskers.unl.edu

2 Biological Systems Engineering, University of Nebraska-Lincoln, Lincoln, $\mathrm{NE}$, USA; Center for Brain, Biology and Behavior, University of Nebraska-Lincoln, Lincoln, NE, USA. email tak8210@gmail.com

3 Special Education and Communication Disorders, University of NebraskaLincoln, Lincoln, NE, USA; Biological Systems Engineering, University of Nebraska-Lincoln, Lincoln, NE, USA; Center for Brain, Biology and Behavior, University of Nebraska-Lincoln, Lincoln, NE, USA.

email yingying.wang@unl.edu

4 Special Education and Communication Disorders, University of NebraskaLincoln, Lincoln, NE, USA; Biological Systems Engineering, University of Nebraska-Lincoln, Lincoln, NE, USA; Center for Brain, Biology and Behavior, University of Nebraska-Lincoln, Lincoln, NE, USA.

email steven.barlow@unl.edu

Corresponding author - R. Custead

\begin{abstract}
Processing dynamic tactile inputs is a primary function of the somatosensory system. Spatial velocity encoding mechanisms by the nervous system are important for skilled movement production and may play a role in recovery of sensorimotor
\end{abstract}

Published in Brain Research 1677 (2017), pp 58-73.

doi 10.1016/j.brainres.2017.09.025

Copyright (C) 2017 Elsevier B.V. Used by permission.

Submitted 30 March 2017; revised 31 August 2017; accepted 20 September 2017; pub-

lished 27 September 2017. 
function following neurological insult. Little is known about tactile velocity encoding in mechanosensory trigeminal networks required for speech, suck, mastication, and facial gesture.

High resolution functional magnetic resonance imaging (fMRI) was used to investigate the neural substrates of velocity encoding in the human orofacial somatosensory system during unilateral saltatory pneumotactile stimulation of perioral and buccal hairy skin in 20 neurotypical adults. A custom multichannel, scalable pneumotactile array consisting of 7 TAC-Cells was used to present 5 stimulus conditions: $5 \mathrm{~cm} / \mathrm{s}, 25 \mathrm{~cm} / \mathrm{s}, 65 \mathrm{~cm} / \mathrm{s}$, ALL-ON synchronous activation, and ALL-OFF. The spatiotemporal organization of whole-brain blood oxygen level-dependent (BOLD) response was analyzed with general linear modeling (GLM) and fitted response estimates of percent signal change to compare activations associated with each velocity, and the main effect of velocity alone.

Sequential saltatory inputs to the right lower face produced localized BOLD responses in 6 key regions of interest (ROI) including; contralateral precentral and postcentral gyri, and ipsilateral precentral, superior temporal (STG), supramarginal gyri (SMG), and cerebellum. The spatiotemporal organization of the evoked BOLD response was highly dependent on velocity, with the greatest amplitude of BOLD signal change recorded during the $5 \mathrm{~cm} / \mathrm{s}$ presentation in the contralateral hemisphere. Temporal analysis of BOLD response by velocity indicated rapid adaptation via a scalability of networks processing changing pneumotactile velocity cues.

Keywords: BOLD, Velocity, Network, Trigeminal, Human

\section{Introduction}

Highly evolved plastic mechanisms within the nervous system allow for accurate interpretations of somatosensory flow associated with passive and active touch, and movement. This information is crucial for motor learning, planning, and execution. Loss or impairment of sensory coding networks has a detrimental effect on motor function, while conversely, even partial recovery of these networks can have a beneficial effect on sensorimotor recovery in disease (Hamdy et al., 1998; Kaelin-Lang et al., 2002; Wu et al., 2006).

In tactile velocity coding, the resultant volley of neural activity from direct skin contact is first mediated by primary afferents and their specialized receptor terminals located in various levels of the dermis in glabrous and hairy skin. These specialized $A \beta$ mechanoreceptors, are either unencapsulated or encapsulated, and are tuned to encode select characteristics of incoming stimuli based on their neural adaptation properties (fast adapting vs slow adapting), receptive field size, best frequency, and absolute threshold sensitivity to mechanical input (Edin et al., 1995; Essick, 1998; Bensmaia, 2008; McGlone and Reilly, 2010). At higher levels in the nervous system, the encoding 
of moving tactile stimulation appears to involve a decomposition of the mostly isomorphic representation of the stimulus at the periphery, into a complex signal of direction and velocity contours that are managed throughout progressive neural circuits (Jones, 1992; Ferezou et al., 2007). Signal refinement is the result of an adaptive relay of competitively filtered neuronal signals throughout select regions of somatosensory and sensorimotor networks. In human limb studies, these regions can include primary somatosensory (postcentral; $\mathrm{SI}$, subareas BA 3a, 3b, 1, 2), secondary somatosensory (SII, BA 40, 43), primary motor (precentral; MI, BA 4), supplemental motor (SMA, BA 6), posterior parietal (PPC, BA 7), prefrontal, and insular cortices, as well as sensorimotor integration regions in the superior temporal gyrus (STG), supramarginal gyrus (SMG), thalamus, and cerebellum (Blatow et al., 2007; Strick et al., 2009; Hu et al., 2012; Huang et al., 2012; Zembrzycki et al., 2013; Schnepel et al., 2014; Rocchi et al., 2016; Jiang et al., 2016).

The perioral region is dominated by slowly adapting (Merkel cell neurites, Ruffini corpuscles) mechanoreceptors, with smaller populations of rapidly adapting (Meissner corpuscles) $A \beta$ mechanoreceptors, but lacks the classic U-function sensitivity assigned to the Pacinian corpuscle (PC) (Barlow, 1987; Johansson et al., 1988; Nordin and Hagbarth, 1989). This is consistent with histological and physiological studies which have not found PC receptors in facial skin (Dubner et al., 1978; Halata and Munger, 1983; Munger and Halata, 1983). Mechanosensory projections from the V2 and V3 divisions of the trigeminal nerve complex are somatotopically mapped in the chief sensory nucleus of $\mathrm{V}$, ventroposteromedial nucleus of the thalamus (VPm), cerebellum, and multiple cortical maps in face S1 and S2 (Welker, 1987; DaSilva et al., 2002; Mottolese et al., 2013). Precise, feedbackdependent orofacial movements, including speech, suck, mastication, and gesture benefit from adaptive neural networks that respond rapidly to facial somatosensory (proprioceptive, tactile) signals resulting from bilabial contact and opening, changes in intraoral air pressure, and conformational changes in perioral skin associated with jaw motion and perioral stretch (Barlow and Bradford, 1996; Barlow, 1998; Capra and Dessem, 1992; Trulsson and Johansson, 2002; Estep and Barlow, 2007; Tomita et al., 2012).

In many research paradigms, stimulation of the facial region in neuroimaging environments has proven to be technically challenging. 
Standard electromechanical- and piezoceramic/piezoelectric-based stimulating devices require feed wires and large source currents to function, both of which can interfere with MR signal acquisition, or become heated by radiofrequency pulses if not properly shielded (Blankenburg et al., 2003; Antal et al., 2014; Lipworth et al., 2015). Similarly, some pneumatic stimulators involve complex set-ups, and are not easily adapted to applications that include participants with neurological disease, or time-restricted imaging paradigms (Servos et al., 1999; Briggs et al., 2004; Huang et al., 2012, Dresel et al., 2008). The pneumotactile stimulator in the present study (GALILEO Somatosensory ${ }^{\mathrm{TM}}$ ) uses a chambered tactile cell (TAC-Cell) which can be applied quickly to the skin of any population using double adhesive tape collars, with scalable and programmable control to create saltatory tactile arrays unique to study designs. Recent studies utilizing pulse trains of pneumotactile stimulation at different stimulus rates (2-6 $\mathrm{Hz}$ ) with just a single TAC-Cell placed on either the glabrous hand or lower face have shown significant and unique short- and long-term adaptation patterns in S1, S2, and posterior parietal cortex (PPC) using magnetoencephalography source localization methods (Popescu et al., 2010, 2013; Venkatesan et al., 2010, 2014), and electroencephalography (Custead et al., 2015).

The aim of the present study is to extend our previous work from single channel TAC-Cell stimulation at a single skin location, to a multichannel TAC-Cell array to map the brain's evoked fMRI BOLD network in response to dynamically patterned spatial arrays programmed to generate saltation velocities over the perioral and buccal surface of the lower face. Additionally, we extend our research paradigm by utilizing high-resolution fMRI to; (1) include neurovascular coupling links to peripheral stimulation (2) improve spatial resolution that may be combined with high temporal resolution EEG/MEG in next-step projects, and (3) begin to explore regions of activity that are involved in whole brain (cortical and deeper subcortical) network activation. We hypothesize that a putative neural 'somatosensory velocity network' with key ROIs in both somatosensory and relevant motor areas of the brain will emerge which scale their hemodynamic response (\%BOLD change) as a function of saltatory velocity. 


\section{Results}

\subsection{Main effect of velocity}

Pneumotactile velocity stimuli delivered to the non-glabrous skin of the right lower face produced BOLD activation in multiple regions of bilateral cortex and cerebellum (Table 1). Statistical parametric mapping (GLM) of the main effect of velocity is shown in Fig. 1 (second level, one-way ANOVA within-subjects, $F(2,38)=11.85, p<0.001$, uncorrected, minimum extent 10 voxels), with all three velocities (5, $25,65 \mathrm{~cm} / \mathrm{s}$ ) inserted into the analysis matrix. The 6 significant activation clusters used for regions of interest (ROI) analysis of putative facial somatosensory velocity processing networks are highlighted (Table $\left.1^{*}\right)$. The largest cluster $\left(\mathrm{k}=\right.$ cluster as $\mathrm{mm}^{3}$ ) of activation encompassed regions of contralateral (left) precentral and postcentral gyri $(k=2686)$. A majority of the remaining large clusters of activation, occurred predominately in cortical and subcortical regions ipsilateral (right) to the stimulus, which included right superior temporal gyrus (STG), right supramarginal gyrus $(\mathrm{SMG}),(\mathrm{k}=585)$, right precentral

Table 1. Main Effect of Saltatory Pneumotactile Velocity Stimulation. Whole brain results (second level group analysis of 20 participants, one-way ANOVA within-subjects design). Data represents all 3 velocities $(5,25,65 \mathrm{~cm} / \mathrm{s})$ inserted into analysis matrix. The 6 significant activation clusters used for region of interest (ROI) analysis of putative facial sensorimotor velocity processing networks are highlighted $\left.{ }^{*}\right)$. Note: Both $L$ precentral and postcentral gyri comprise cluster '2686,' and both R superior temporal and R supramarginal gyri comprise cluster '585.'

Main Effect of Velocity

Region

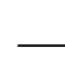

L Precentral Gyrus*

L Postcentral Gyrus*

R Superior Temporal Gyrus*

R Supramarginal Gyrus*

$\mathrm{R}$ Cerebellum (VI)*

R Inferior Frontal Gyrus

R Precentral Gyrus*

L Posterior-Medial Frontal

L Middle Occipital Gyrus

L Cerebellum (VI)

R Middle Occipital Gyrus

R Inferior Occipital Gyrus

R Rolandic Operculum

\begin{tabular}{lrrrrr} 
& & & \multicolumn{3}{c}{ MNI Coordinates } \\
\cline { 5 - 6 } $\begin{array}{l}\text { Laterality } \\
\text { (re: stimulus })\end{array}$ & $\begin{array}{r}\text { Extent } \\
\left(k=m m^{3}\right)\end{array}$ & $F$-score & $x$ & $y$ & $z$ \\
Contra & 2686 & 37.81 & -57 & 3 & 40 \\
Contra & & 35.37 & -49.5 & -24.5 & 25 \\
Ipsi & 585 & 26.57 & 51 & -32 & 20 \\
Ipsi & & 15.66 & 68 & -22 & 22.5 \\
Ipsi & 144 & 24.78 & 26 & -57 & -23 \\
Ipsi & 236 & 23.53 & 58 & 6 & 30 \\
Ipsi & & 17.11 & 50.5 & 0.5 & 52.5 \\
Contra & 264 & 21.33 & -7 & -2 & 63 \\
Contra & 244 & 20.84 & -35 & -90 & 23 \\
Contra & 75 & 14.42 & -22 & -60 & -25 \\
Ipsi & 26 & 11.28 & 41 & -87 & 13 \\
Ipsi & 24 & 10.38 & 38 & -72 & -3 \\
Ipsi & 5 & 9.21 & 46 & -5 & 13 \\
\hline
\end{tabular}




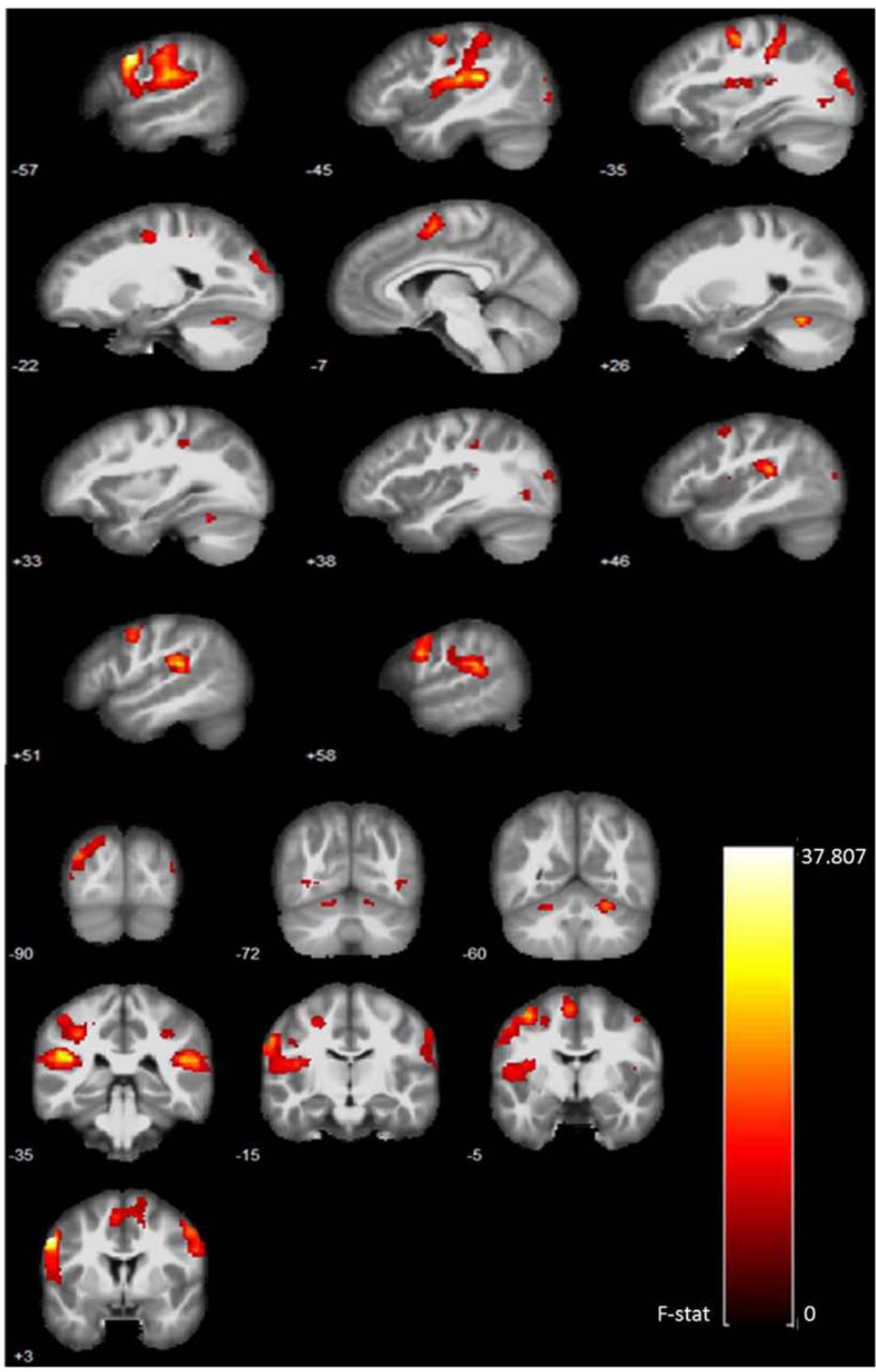

Fig. 1. Main Effect of Saltatory Pneumotactile Velocity Stimulation. Whole brain activation corresponding to Table 1. (a) Images show pooled positive [voxels exceeding height threshold of $F(2,38)=11.85, p<0.001$, uncorrected; $(b)$ extent threshold $k$ $>10$ voxels] BOLD data from 20 participants. 
Table 2. Velocities > ALL-OFF Control Condition. One sample $t$-test results [height threshold of $\mathrm{t}(19)=3.58, \mathrm{p}<0.001$, uncorrected; extent threshold $\mathrm{k}>10$ voxels] of BOLD activation associated with individual velocities compared to all TAC-Cells off.

\begin{tabular}{|c|c|c|c|c|c|c|c|}
\hline \multicolumn{2}{|c|}{ Velocities > ALL-OFF Control } & \multirow[b]{2}{*}{$\begin{array}{l}\text { Laterality } \\
\text { (re: stimulus) }\end{array}$} & \multirow[b]{2}{*}{$\begin{array}{r}\text { Extent } \\
\left(k=m m^{3}\right)\end{array}$} & \multirow[b]{2}{*}{$T$-score } & \multicolumn{3}{|c|}{ MNI Coordinates } \\
\hline & Region & & & & $x$ & $y$ & $z$ \\
\hline \multirow[t]{5}{*}{$5 \mathrm{~cm} / \mathrm{s}>\mathrm{ALL}-\mathrm{OFF}$} & L Superior Temporal Gyrus & Contra & 2020 & 9.72 & -45 & -37 & 20 \\
\hline & R Rolandic Operculum & Ipsi & 756 & 7.96 & 53 & -25 & 23 \\
\hline & R Cerebellum (VI) & Ipsi & 134 & 6.45 & 16 & -70 & -23 \\
\hline & R Precentral Gyrus & Ipsi & 140 & 5.30 & 58 & 3 & 45 \\
\hline & L Postcentral Gyrus & Contra & 128 & 5.18 & -32 & -40 & 53 \\
\hline \multirow[t]{3}{*}{$25 \mathrm{~cm} / \mathrm{s}>\mathrm{ALL}-\mathrm{OFF}$} & L Postcentral Gyrus & Contra & 1031 & 8.63 & -60 & -17 & 43 \\
\hline & R Superior Temporal Gyrus & Ipsi & 306 & 5.55 & 51 & -27 & 20 \\
\hline & R Rolandic Operculum & Ipsi & 23 & 4.28 & 53 & -10 & 15 \\
\hline \multirow[t]{2}{*}{$65 \mathrm{~cm} / \mathrm{s}>\mathrm{ALL}-\mathrm{OFF}$} & L Postcentral Gyrus & Contra & 287 & 5.10 & -57 & -22 & 20 \\
\hline & R Rolandic Operculum & Ipsi & 30 & 4.35 & 58 & -20 & 23 \\
\hline
\end{tabular}

gyrus $(k=236)$, Rolandic operculum $(k=5)$, and right cerebellum (lobule VI, $\mathrm{k}=144$ ).

Although main effect clusters were labeled broadly according to probabilistic cytoarchitectonic maps based mostly on limb stimulation (SMP Anatomy toolbox), the data reported here matched closely with regions of activation associated with orofacial sensory stimulation reported in other studies (Miyamoto et al., 2005; Huang and Sereno, 2007; Eickhoff et al., 2008; Grabski et al., 2012). The robust bilateral activation seen in main effect data also appears to be consistent with previous human trigeminal studies, particularly when strong stimulation is applied to both upper (trigeminal V2) and lower (V3) lips (lannetti et al., 2003; Dresel et al., 2008; Sato et al., 2015).

\subsection{Velocities > control conditions}

Results of one-sample t-tests [t $(19)=3.58, p<0.001$, uncorrected] used to monitor the change in BOLD signal associated with individual velocities $(5,25,65 \mathrm{~cm} / \mathrm{s})$ compared to the two control conditions (ALL-OFF, ALL-ON), showed tight BOLD modulation corresponding to changes in saltatory stimulus velocity. Positive BOLD activation associated with velocities compared to the control condition 'ALL-OFF' are shown in Table 2. In this contrast, BOLD activation was seen at all three velocity presentations, with the largest spatial extent of activation seen in the ' $5 \mathrm{~cm} / \mathrm{s}>$ ALL-OFF' condition (Figs. 2.1.a, 2.2.a) with 


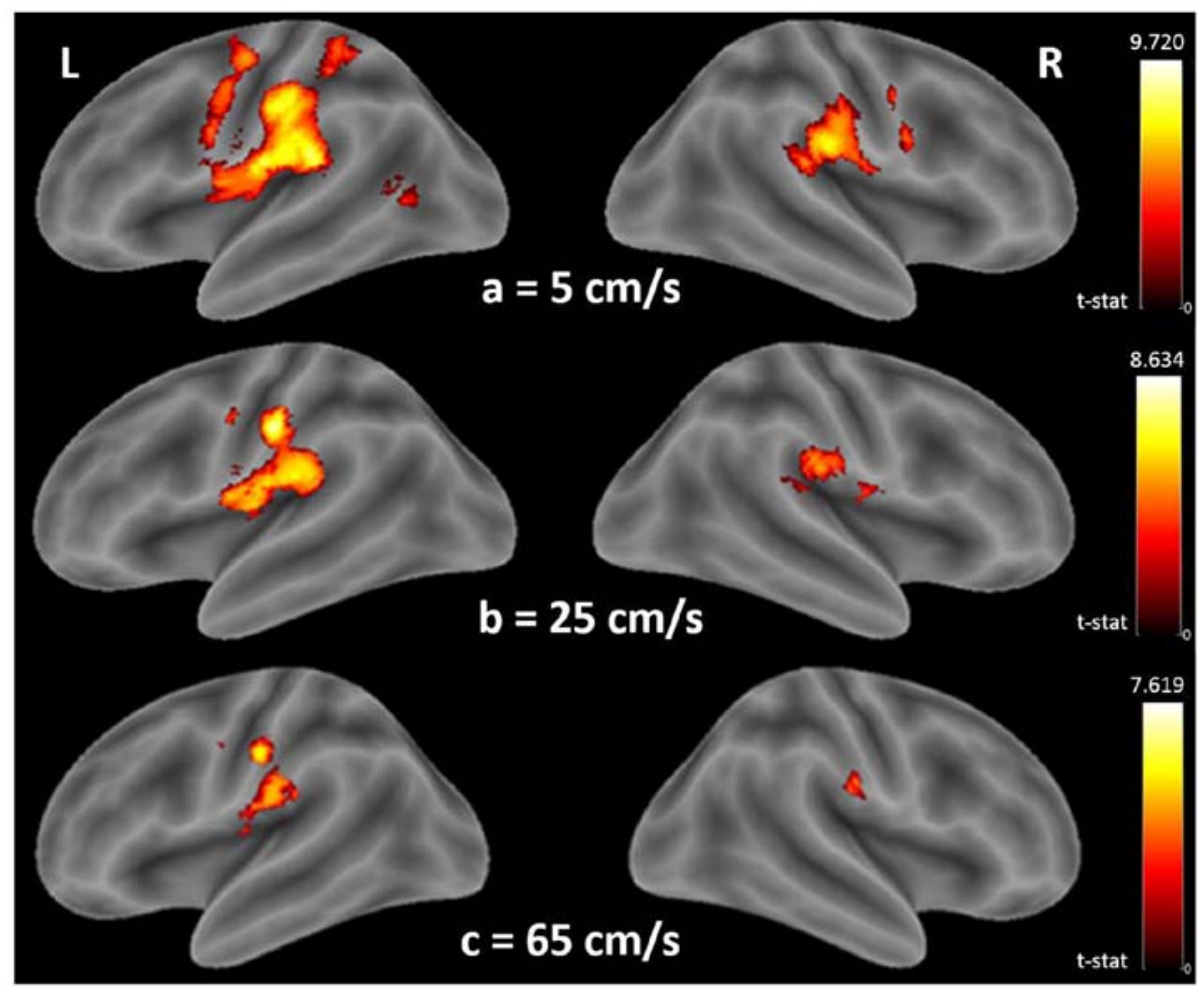

Fig. 2.1. Velocities > ALL-OFF Control Condition-Cortex. One sample $t$-test activation corresponding to Table 2. Images show positive cortical activation on an inflated surface where $a=5 \mathrm{~cm} / \mathrm{s}, \mathrm{b}=25 \mathrm{~cm} / \mathrm{s}$, and $\mathrm{c}=65 \mathrm{~cm} / \mathrm{s}$ velocities.

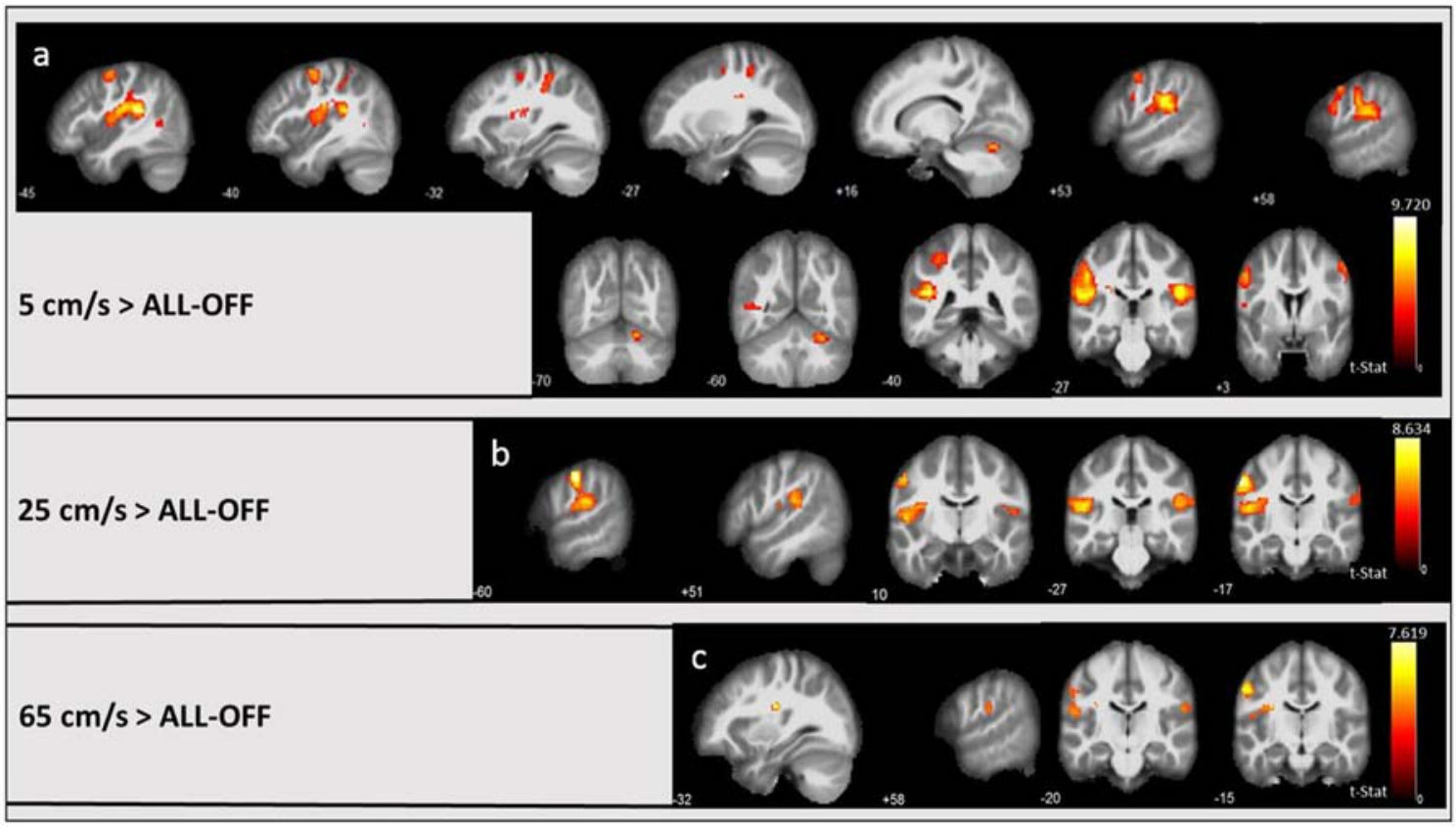

Fig. 2.2. Velocities > ALL-OFF Control Condition-Whole Brain. One sample $t$-test activation corresponding to Table 2 . Images show positive whole brain activation during $5 \mathrm{~cm} / \mathrm{s}, 25 \mathrm{~cm} / \mathrm{s}$, and $65 \mathrm{~cm} / \mathrm{s}$ velocities with the ALL-OFF condition used as a comparative baseline. 
Table 3. Velocities > ALL-ON Control Condition. One sample $t$-test results [height threshold of $\mathrm{t}(19)=3.58, \mathrm{p}<0.001$, uncorrected; extent threshold $\mathrm{k}>10$ voxels] of BOLD activation associated with individual velocities compared to all TAC-Cells on simultaneously.

\begin{tabular}{|c|c|c|c|c|c|c|c|}
\hline \multicolumn{3}{|c|}{ Velocities > ALL-ON Control } & \multirow[b]{2}{*}{$\begin{array}{r}\text { Extent } \\
\left(\mathrm{k}=\mathrm{mm}^{3}\right)\end{array}$} & \multirow[b]{2}{*}{ T-score } & \multicolumn{3}{|c|}{ MNI Coordinates } \\
\hline & Region & $\begin{array}{l}\text { Laterality } \\
\text { (re: stimulus) }\end{array}$ & & & $\mathrm{x}$ & y & z \\
\hline \multirow[t]{6}{*}{$5 \mathrm{~cm} / \mathrm{s}>\mathrm{ALL}-\mathrm{ON}$} & R Postcentral Gyrus & Ipsi & 533 & 9.31 & 63 & -20 & 43 \\
\hline & L Postcentral Gyrus & Contra & 2002 & 8.69 & -52 & -25 & 38 \\
\hline & R Rolandic Operculum & Ipsi & 163 & 6.90 & 58 & 6 & 30 \\
\hline & L Rolandic Operculum & Contra & 52 & 5.38 & -47 & -5 & 10 \\
\hline & R Cerebellum (VI) & Ipsi & 71 & 5.24 & 21 & -65 & -23 \\
\hline & L Posterior-Medial Frontal & Contra & 57 & 4.93 & -7 & 1 & 60 \\
\hline $25 \mathrm{~cm} / \mathrm{s}>\mathrm{ALL}-\mathrm{ON}$ & L Postcentral Gyrus & Contra & 225 & 8.18 & -62 & -15 & 43 \\
\hline $65 \mathrm{~cm} / \mathrm{s}>\mathrm{ALL}-\mathrm{ON}$ & L Postcentral Gyrus & Contra & 76 & 5.47 & -52 & -12 & 40 \\
\hline
\end{tabular}

significant clusters in regions of contralateral (left) STG $(k=2020)$ and postcentral gyrus $(k=128)$, as well as ipsilateral (right) precentral gyrus $(k=140)$, deep operculum $(k=756)$, and cerebellum (lobule $\mathrm{VI}, \mathrm{k}=134$ ). In the ' $25 \mathrm{~cm} / \mathrm{s}>$ ALL-OFF' contrast (Figs. 2.1.b, 2.2.b), bilateral activation was again present in left postcentral gyrus $(\mathrm{k}=$ 1031) right STG $(k=306)$ and right operculum $(k=23)$, but reduced in spatial extent, with no cerebellar response recorded. In the ' $65 \mathrm{~cm} /$ $\mathrm{s}>$ ALL-OFF' contrast (Figs. 2.1.c, 2.2.c), the spatial extent of bilateral activation was further reduced, with only a single cluster recorded in left postcentral gyrus $(k=287)$ and ipsilateral operculum $(k=30)$.

As shown in Table 3, when each velocity was compared to the 'ALL-ON' (stimulator cells activated simultaneously at $1 \mathrm{~Hz}$ ) control condition, positive BOLD activation was again observed at all three velocity presentations $(5,25,65 \mathrm{~cm} / \mathrm{s})$, with bilateral cortical activation noted only at the ' $5 \mathrm{~cm} / \mathrm{s}>$ ALL-ON' condition (Figs. 3.1. a, 3.2.a) in left postcentral gyrus $(k=2002)$, posterior frontal gyrus $(k=57)$, operculum ( $k=52)$, and right postcentral gyrus $(k=533)$, operculum $(k=163)$, and right cerebellum $(k=71)$. In the ' $25 \mathrm{~cm} / \mathrm{s}>$ ALL-ON' contrast (Figs. 3.1.b, 3.2.b), and the ' $65 \mathrm{~cm} / \mathrm{s}>$ ALLON' (Figs. 3.1.c, 3.2.c) contrast, only one significant cluster emerged in the left postcentral gyrus ( $k=225$, and $k=76$ respectively). 


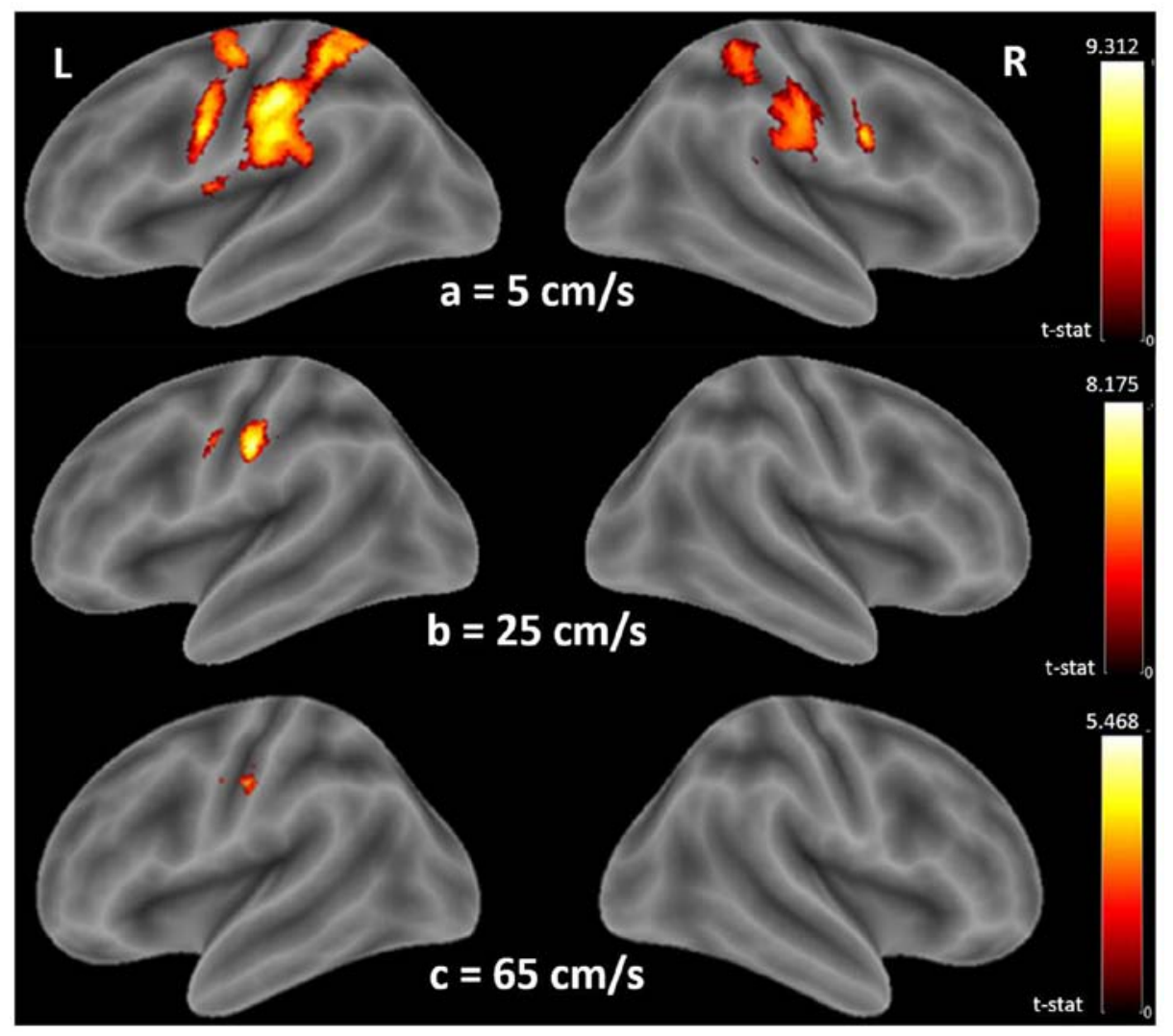

Fig. 3.1. Velocities > ALL-ON Control Condition-Cortex. One sample $t$-test activation corresponding to Table 2. Images show positive cortical activation on an inflated surface where $a=5 \mathrm{~cm} / \mathrm{s}, b=25 \mathrm{~cm} / \mathrm{s}$, and $c=65 \mathrm{~cm} / \mathrm{s}$ velocities.

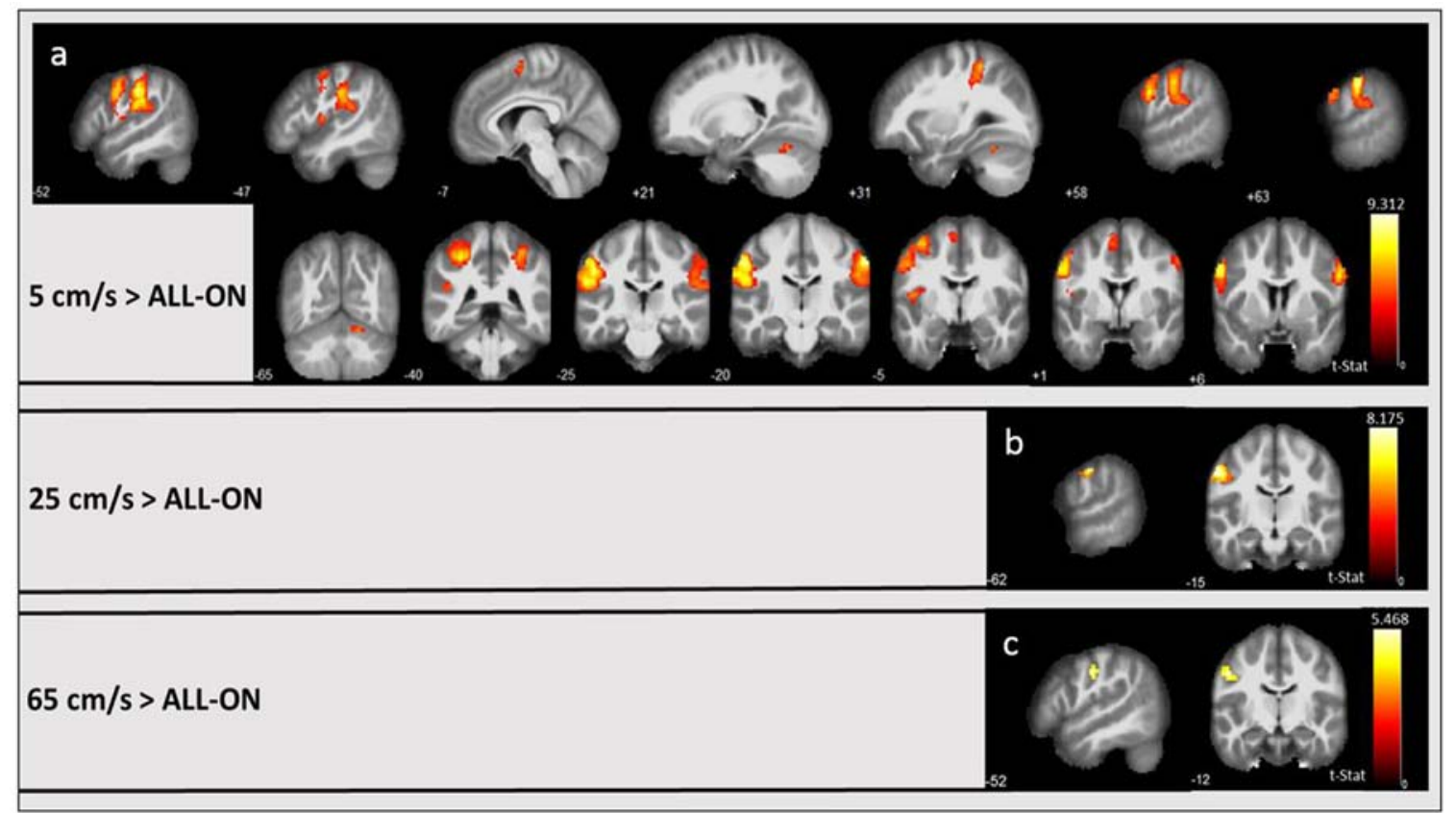

Fig. 3.2. Velocities > ALL-ON Control Condition-Whole Brain. One sample $t$-test activation corresponding to Table 3 . Images show positive whole brain activation during $5 \mathrm{~cm} / \mathrm{s}, 25 \mathrm{~cm} / \mathrm{s}$, and $65 \mathrm{~cm} / \mathrm{s}$ velocities with the ALL-ON condition used as a comparative baseline. 


\subsection{ROI analysis: velocity dependent \%BOLD signal change}

Region of interest (ROI) analysis was conducted on main effect cluster maximas at corresponding MNI coordinates. Figs. 4.1.a-4.6.a shows whole brain ANOVA data ( $F$ statistic) of 20 participants. Bars (Figs. 4.1.b-4.6.b) represent estimates of mean \%BOLD signal change by

\section{Left Postcentral Gyrus}
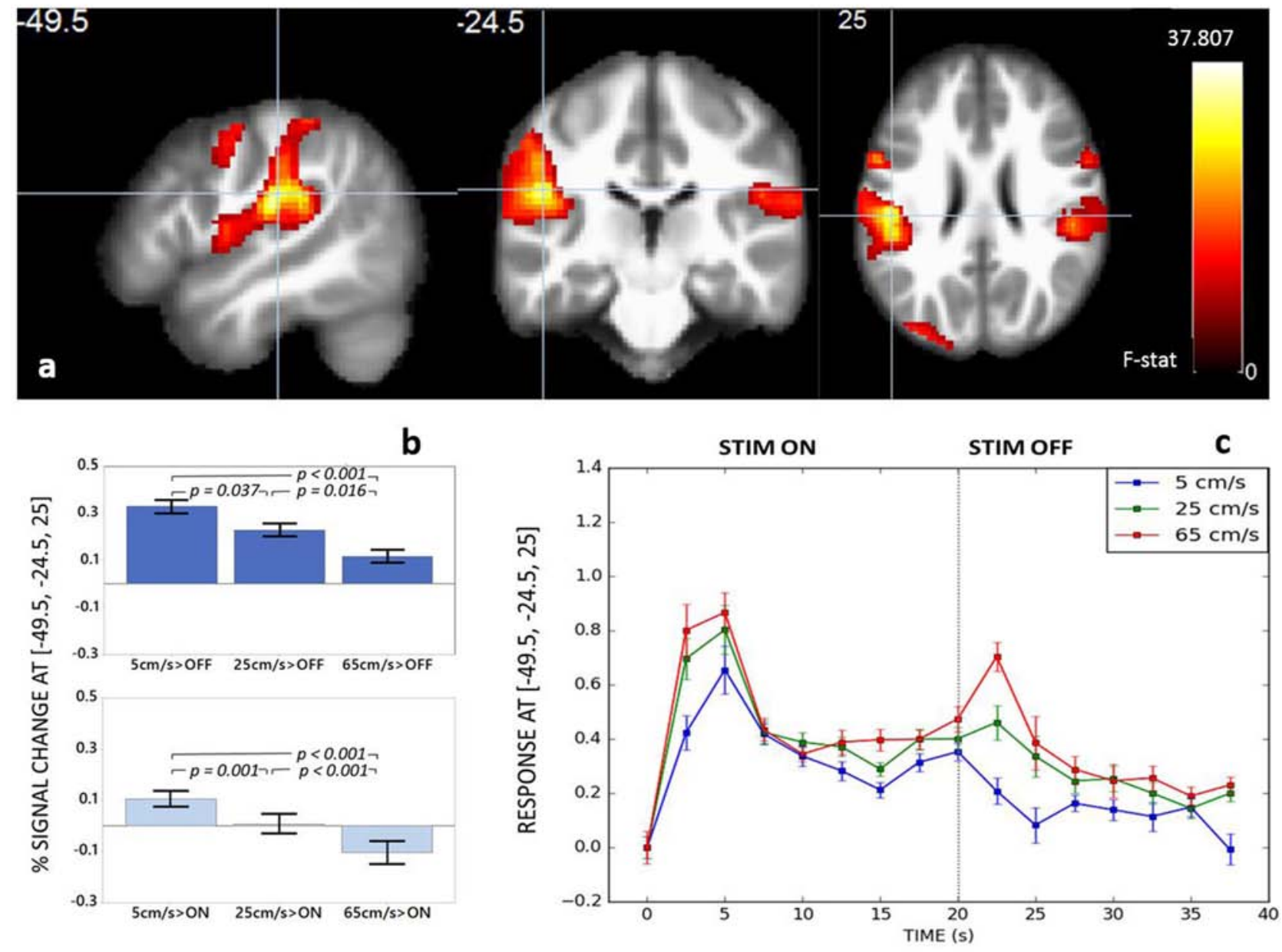

Fig. 4.1-4.6. ROI Analysis. MRI images (a) show main effect data from 20 participants at specified MNI coordinates (each ROI). Colored bars (b) represent overall $\%$ BOLD signal change by condition $(5 \mathrm{~cm} / \mathrm{s}>$ ALL-OFF, $25 \mathrm{~cm} / \mathrm{s}>$ ALL-OFF, $65 \mathrm{~cm} / \mathrm{s}$ $>$ ALL-OFF and $5 \mathrm{~cm} / \mathrm{s}>$ ALL-ON, $25 \mathrm{~cm} / \mathrm{s}>$ ALL-ON, $65 \mathrm{~cm} / \mathrm{s}>$ ALL-ON) in each $\mathrm{ROI}$ with pairwise comparisons $(\mathrm{N}=58, \mathrm{p}<0.05, \mathrm{Cl} 0.95)$ used to estimate differences in mean BOLD response by velocity. Line graphs (c) represent fitted response estimates of cluster maximas at these $\mathrm{MNI}$ coordinates plotted against scan/time (20 s stimulation ON/20 s stimulation OFF). Error bars in (b) and (c) indicate 1 SEM.

(4.1) ROI Left Postcentral Gyrus. MRI images show main effect data from 20 participants at MNI coordinates $(-49.5,-24.5,25)$. 


\section{Left Precentral Gyrus}

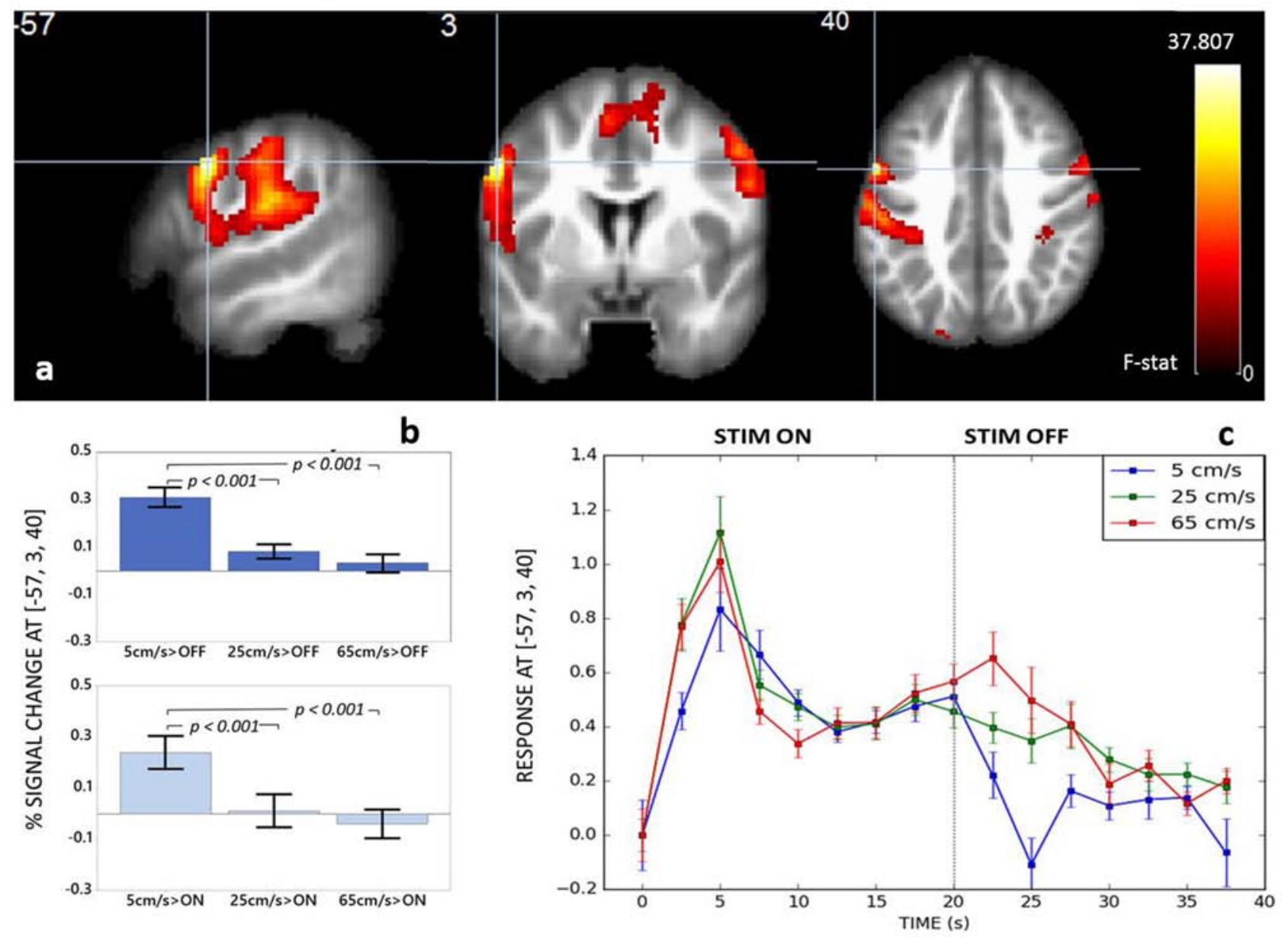

Fig. 4 (continued) (4.2) ROI Left Precentral Gyrus. MRI images show main effect data from 20 participants at MNI coordinates $(-57,3,40)$.

condition $(5 \mathrm{~cm} / \mathrm{s}>$ ALL-OFF, $5 \mathrm{~cm} / \mathrm{s}>$ ALL-ON, $25 \mathrm{~cm} / \mathrm{s}>$ ALL-OFF, $25 \mathrm{~cm} / \mathrm{s}>$ ALL-ON, $65 \mathrm{~cm} / \mathrm{s}>$ ALL-OFF, $65 \mathrm{~cm}>$ ALL-ON) in each ROI. In all regions, the mean \%BOLD response was highly dependent on velocity, with the greatest signal change occurring in the contralateral hemisphere (precentral and postcentral gyri). Comparisons of positive $B O L D$ response by velocities also indicated that in all regions, \%BOLD signal change was greatest during at the $5 \mathrm{~cm} / \mathrm{s}$ (lowest) velocity presentation, with \% signal change decreasing as stimulus velocity increased $(25 \mathrm{~cm} / \mathrm{s}, 65 \mathrm{~cm} / \mathrm{s})$. Post-hoc Tukey pairwise comparisons $(\mathrm{N}=58, \mathrm{p}<0.05, \mathrm{Cl} 0.95)$ of differences in mean \%BOLD response by 


\section{Right Precentral Gyrus}
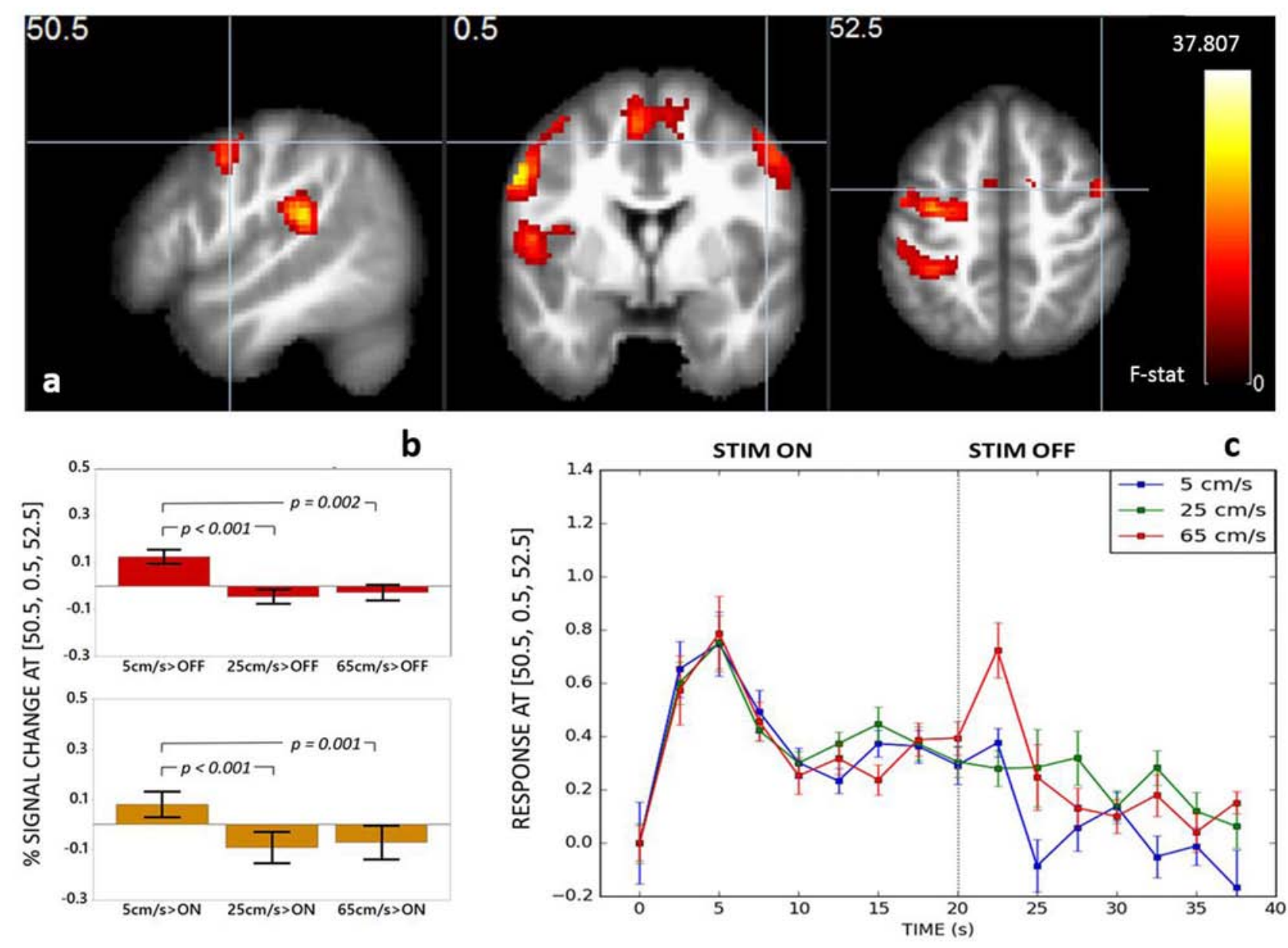

Fig. 4 (continued) (4.3) ROI Right Precentral Gyrus. MRI images show main effect data from 20 participants at MNI coordinates $(50.5,0.5,52.5)$.

velocity showed that in all ROI, and compared to either the 'ALL-OFF' or 'ALL-ON' control condition, the $5 \mathrm{~cm} / \mathrm{s}$ (lowest) velocity response was statistically different from the $65 \mathrm{~cm} / \mathrm{s}$ (highest) velocity response. In ROI contralateral to the stimulus, the $5 \mathrm{~cm} / \mathrm{s}$ response was significantly different from the $25 \mathrm{~cm} / \mathrm{s}$ response (left postcentral gyrus $p=$ 0.037, 'ALL-OFF', $p=0.001$, 'ALL-ON', left precentral gyrus, $(p<0.001$, 'ALL-OFF', $p<0.001$, 'ALL-ON'), while in ROI ipsilateral to the stimulus, the two low velocity responses $(5,25 \mathrm{~cm} / \mathrm{s})$ differed significantly only in right precentral gyrus ( $p<0.001$, 'ALLOFF', $p<0.001$, 'ALL-ON') and cerebellum ( $p=0.001$, 'ALL-OFF', $p<0.001$, 'ALL-ON'). Additionally, all 


\section{Right Superior Temporal Gyrus}
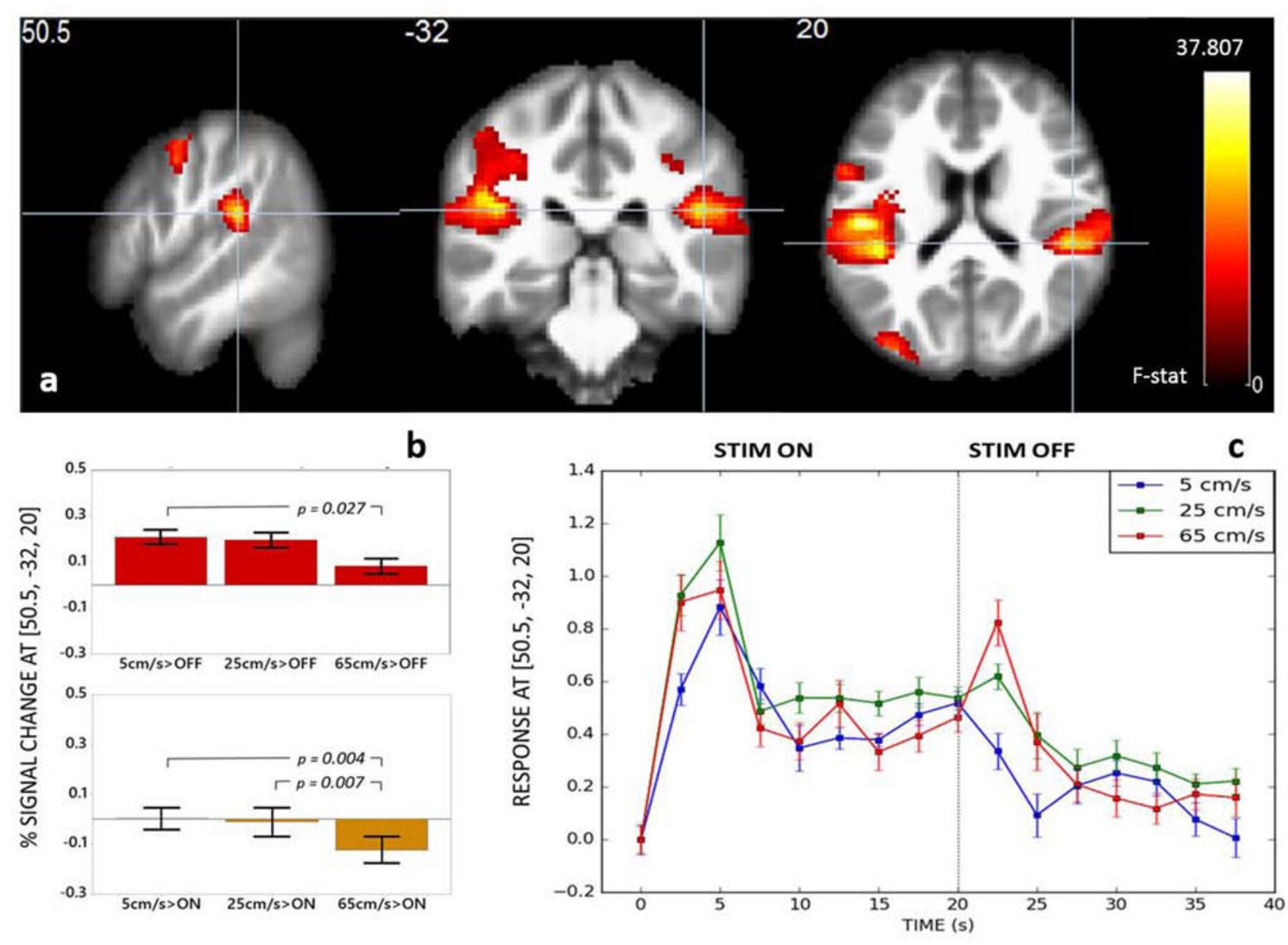

Fig. 4 (continued) (4.4) ROI Right Superior Temporal Gyrus. MRI images show main effect data from 20 participants at $\mathrm{MNI}$ coordinates $(50.5,-32,20)$.

ROI 'ALL-ON' analysis showed a large positive \%BOLD signal change at the $5 \mathrm{~cm} / \mathrm{s}$ velocity, with a shift to a negative \%BOLD signal change in both the $25 \mathrm{~cm} / \mathrm{s}$ and $65 \mathrm{~cm} / \mathrm{s}$ velocity.

\subsection{ROI Analysis: Temporal characteristics of BOLD signal}

Fitted response estimates of cluster maximas for each ROI plotted against scan/time (main effect data at corresponding MNI coordinates) are shown in Figs. 4.1.c-4.6.c. ROI hemodynamics are shown as the time course of the BOLD response by velocity condition over a 


\section{Right Supramarginal Gyrus}
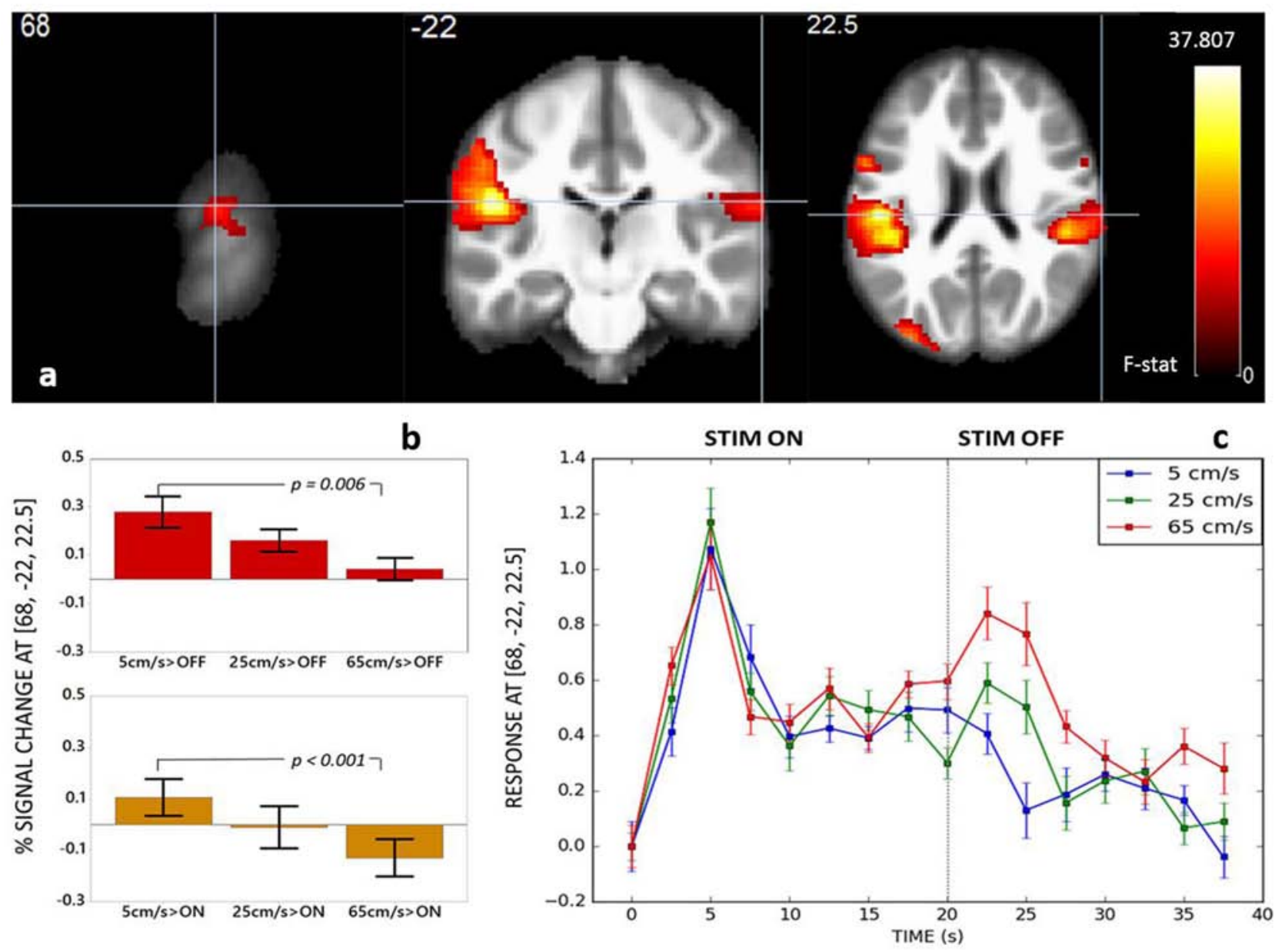

Fig. 4 (continued) (4.5) ROI Right Supramarginal Gyrus. MRI images show main effect data from 20 participants at MNI coordinates $(68,-22,22.5)$.

40-s acquisition block (20 s stimulation followed by $20 \mathrm{~s}$ off). Overall, the largest peak hemodynamic response across all regions occurred 3-5 s from the onset of pulsed somatosensory stimulation, with rapid adaptation occurring by $10 \mathrm{~s}$ into stimulation. Additionally, in all ROIs there was a peak of smaller amplitude approximately $5 \mathrm{~s}$ following the cessation of stimulation, indicative of a 'stimulus off' response. Interestingly, in all ROls except right cerebellum, the highest velocity $(65 \mathrm{~cm} / \mathrm{s})$ 'stimulus off' response resulted in a positive response peak, while the lowest velocity $(5 \mathrm{~cm} / \mathrm{s})$ 'stimulus off' response resulted in a negative drop in signal intensity. This transformation of the amplitude 


\section{Right Cerebellum}
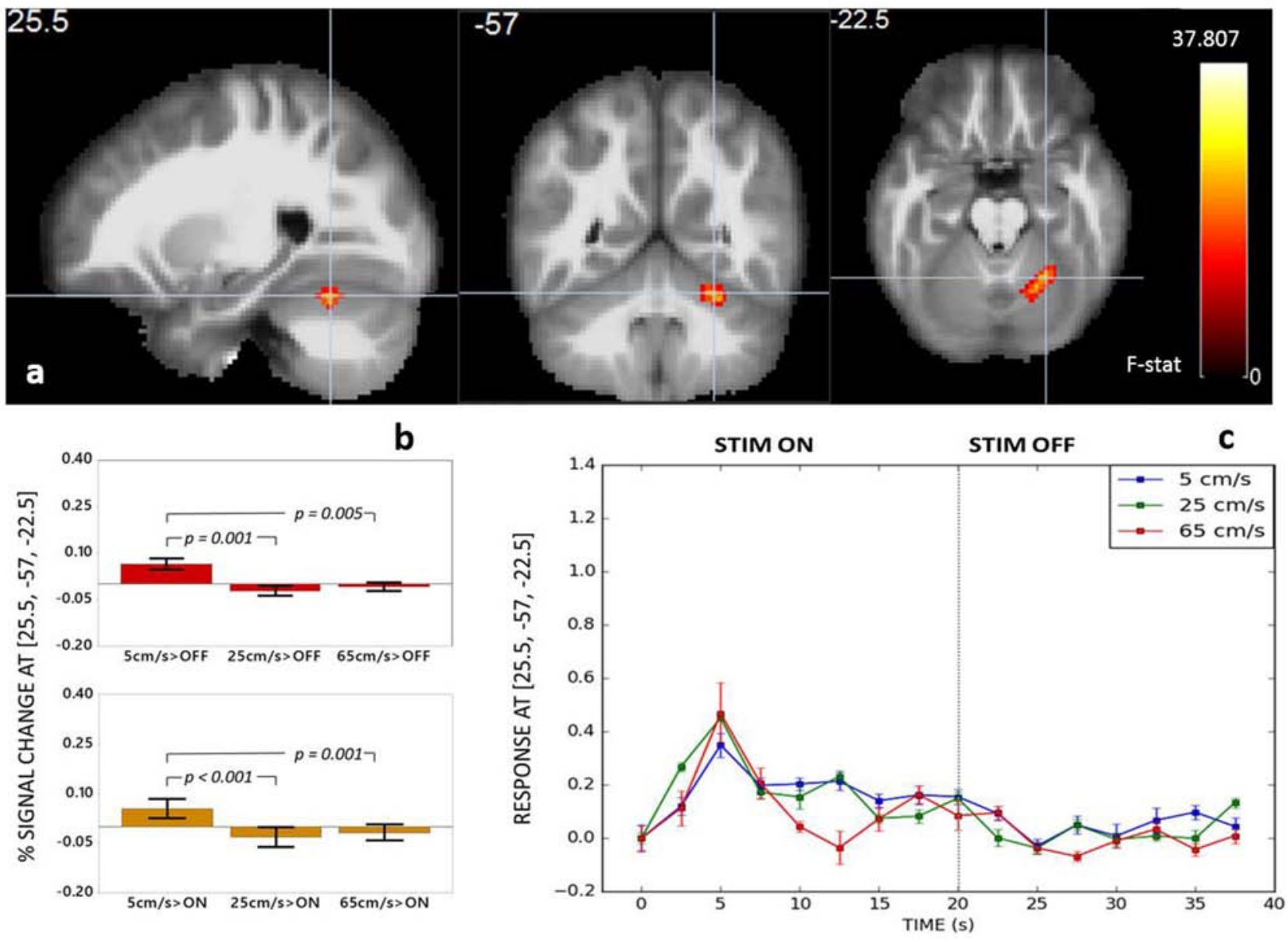

Fig. 4 (continued) (4.6) ROI Right Cerebellum. MRI images show main effect data from 20 participants at MNI coordinates $(25.5,-57,-22.5)$.

and contour of the response curve may indicate a management of signal by dedicated sensory processing regions selectively sensitive to changes in stimulus velocity.

\section{Discussion}

In our paradigm, we found that BOLD responses from neurotypical adult subjects were highly dependent on the velocity of saltatory phased-array pneumotactile stimulation applied unilaterally to the lower face. In addition to activation in contralateral facial somatosen- 
sory and sensorimotor regions (left precentral and postcentral gyri), we also report significant activation in the hemisphere ipsilateral to the stimulus in precentral gyrus, STG, SMG, deeper regions of operculum, and cerebellum. Temporally, BOLD responses over a $40 \mathrm{~s}$ on/ off stimulation block showed hemodynamic shifts with rapid adaptation not only at the onset of somatosensory stimulation, but also at stimulus cessation.

The transformation of BOLD activation as a function of velocity is likely attributed to changes in network processing of tactile stimulation (Kohn and Whitsel, 2002; Lundblad et al., 2011; Pei and Bensmaia, 2014). Physiologically, suprathreshold mechanical touch signals start as widespread, relatively diffuse activity across somatosensory macrocolumns that are driven by the characteristics of the stimulus. Over a time scale of milliseconds, cortical macrocolumn activity fractionates into refined stimulus-specific patterns of distinctly active minicolumns (Rowe et al., 1985; Favorov and Diamond, 1990; Whitsel et al., 1999; Iwamura et al., 2002; Hu et al., 2012). This allows for a dynamic representation of tactile stimulus through a type of competitive selection of neuron subsets whose feature-tuning properties most closely match those of the stimulus (Tommerdahl et al., 2005, 2006; Dileep and Hawkins, 2009; Peron et al., 2015). In the present paradigm, modulation of BOLD activation was associated with changes in the velocity of a stimulus over a set block of time. While the velocity of the stimulus was varied, neuronal populations may be driven by changes in the temporal density of pneumotactile stimulation, as there are simply more stimulus pulses delivered in the $20 \mathrm{~s}$ block at the higher velocities $(25,65 \mathrm{~cm} / \mathrm{s})$ compared to the $5 \mathrm{~cm} / \mathrm{s}$ condition. To monitor this effect in future paradigms, a scrambled motion condition at a set velocity may provide more information on this phenomenon. It is interesting to note however, that the largest spatial extent of BOLD activation was recorded during the lowest velocity presentation with the lowest temporal density $(5 \mathrm{~cm} / \mathrm{s})$, which may be indicative a habituation or repetition suppression response in neuronal populations deciphering tactile cues.

Along with varied velocity characteristics of the stimulus, the scalable pneumotactile array used in our paradigm provided discontinuous (saltatory), sequential stimulation. Intriguingly, psychophysical study of human responses to brief, discrete, consecutive tactile stimu- 
lation, has shown that perception of such stimuli can be affected by differing inter-stimulus timing intervals. In some cases, tactile input, stimulus timing and spatial position are integrated in a phenomenon known as 'fusion,' or tactile 'funneling,' as in the 'cutaneous rabbit' effect (Chen et al., 2003; Warren et al., 2011; Kitazawa, 2013). When humans are asked to judge the distance between two punctate taps delivered in rapid succession to the skin, they consistently underestimate the distance of the taps, and perceive the distance between taps to be shorter as the time interval between taps is reduced (Goldreich, 2007). In stimuli involving multiple punctate taps in rapid succession to neighboring skin sites, perceived locations are nearly always shifted toward the subsequent stimuli (Geldard and Sherrick, 1972; Goldreich and Tong, 2013). It seems possible in the present study, that the unique and rapid alterations of the spatial extent (Figs. 2.1, 2.2, $3.1,3.2$ ) and intensity of BOLD signals (\% signal change Figs. 4.1-6b) across all three $(5,25,65 \mathrm{~cm} / \mathrm{s})$ velocities was associated with this type of neural fusion, particularly during the higher $(65 \mathrm{~cm} / \mathrm{s})$ velocity presentations. Similarly, differences in stimulus velocity and/or frequency (number of stimuli in a series) may be associated with rapid adaptation or habituation in response to changes in stimulation.

Human psychophysical research has shown that for tactile acuity (during skin brushing or linear rolling stimulation), the optimal range for accurate discrimination of skin traverse velocity is between 3 and $30 \mathrm{~cm} / \mathrm{s}$ (Whitsel et al., 1986, 1999; Dreyer et al., 1978; Lamb 1983; Essick et al., 1988a,b, 1991, 1992; Luken et al., 2011; Ackerley et al, 2014). Although subjects are still able to discern characteristics of moving stimuli presented at higher velocities, performance on velocity discrimination tasks deteriorates rapidly at traverse velocities exceeding $50 \mathrm{~cm} / \mathrm{s}$. From a central processing standpoint, this tends to indicate that for stimulus velocities greater than $50 \mathrm{~cm} / \mathrm{s}$ as in this study, neural circuits are processing inputs through different, conceivably "periodicity consolidating" networks in higher levels of cortex (Darian-Smith et al., 1984). Also, as stimulus velocity increases, it may be that there is enough loss of temporal and spatial detail that discrimination accuracy is reduced (Johnson and Lamb, 1981; Lamb, 1983). In some cases, moving tactile stimulation presented at velocities at the low end of tactile acuity, such as the $5 \mathrm{~cm} / \mathrm{s}$ presentation here, appear to be processed in cortical networks as discrete stimuli, rather than a constant motion across the skin (Phillips and Johnson, 1985; Trulsson et 
al., 2000; Wacker et al., 2011; Dépeault et al., 2013). An explanation for this may be that at some velocity threshold, networks of somatosensory neurons switch from processing individual stimuli to processing temporal cues corresponding to consecutive, directional stimulation (Szaniszlo et al., 1998; Tommerdahl et al., 2010). To capture dynamic BOLD activation at the low and high end of this perceptual range, a low but continuous velocity $(5 \mathrm{~cm} / \mathrm{s})$, a mid-range velocity $(25 \mathrm{~cm} / \mathrm{s})$, and a relatively high but discernable velocity $(65 \mathrm{~cm} / \mathrm{s})$ was selected for use in this first study.

Our findings of bilateral cortical activation during velocity varied pneumotactile stimulation matches other human trigeminal studies, and also may reflect the activation of cortical integration areas sensitive to temporal synchrony during sensation and sensory-guided movement such as posterior parietal cortices (PPC), superior temporal sulcus (STS) and ventral intraparietal area (VIP) (Beauchamp et al., 2010; Sereno and Huang, 2014, Chen et al., 2017). Long-range connectivity from ipsilateral trigeminal inputs has been demonstrated in animal models, including bilateral projections to $\mathrm{S} 1$, and contralateral S2 and M1 cortices, deep brain nuclei (ventroposteromedial thalamus [VPm] and posteromedial thalamus [POM], dorsolateral striatum), and bilateral temporal association cortices (Aronoff et al., 2010). Both STG and SMG, together with inferior frontal gyrus (IFG) and anterior insula, have been posited to make up part of a 'ventral attention network' responsible for aspects of bottom-up attention and sensorimotor response inhibition (Corbetta et al., 2008; Igelstrom and Graziano, 2017). In oddball paradigms and stimulus driven reorienting of attention tasks, these neural integration hubs form part of the processing network that works to aid in stimulus target detection during unexpected changes in sensory inputs (Downar et al., 2000; Vossel et al., 2012). In instances of visuospatial, auditory and sensory catch trials when an expected target was absent, activations have been reported bilaterally in these integrative networks, with more intense and extensive activation often reported in the right hemisphere as we saw in this paradigm (Macaluso et al., 2002; Kincade et al., 2005; Indovina and Macaluso, 2007). Although not a true odd-ball condition, the changes in velocity, and the switch to either the ALL-OFF or ALL-ON control blocks in this experiment may have resulted in aberrancies of expectation or changes in coincidence detection during repeating trials. For future ROI selection, it should be noted that in main effect data (Table 1, Fig. 
1), there was a cluster of activation in right IFG that was not seen in the 'velocities > control' analysis, while there was fairly robust activation in right operculum, particularly at the lowest $(5 \mathrm{~cm} / \mathrm{s})$ velocity.

In addition to bilateral cortical response, we found significant cerebellar BOLD response to changes in tactile velocity which is consistent with the putative role of the cerebellum in feed-forward control of sensory-guided movements at relatively low velocities. Apart from direct afferent pathways from limb and face to cerebellum, there is an indirect pathway for tactile information to influence the cerebellum via the trigeminal lemniscus to the VPm, which subsequently maps onto orofacial somatosensory cortex. Some outputs from these cerebral orofacial somatosensory areas then descend through corticopontocerebellar pathways to modulate neuronal activity in the dentate nucleus. This represents a feature-rich somatosensory processing loop that acts to enhance proprioceptive and tactile responses useful in motor learning and predictive motor control (Kennedy et al., 1966; Rowland and Jaeger, 2008). In discriminative touch processing, dentate nuclear regions of cerebellum have been shown to respond preferentially to sensory discrimination tasks without movement (Gao et al., 1996; Parsons et al., 1997; Küper et al., 2011; Ohmae et al., 2013), and have extensive connectivity to the midbrain red nucleus which has been hypothesized to play a key role in touch processing (Liu et al., 2000; Gruber and Gould, 2010), and even functional recovery due to cortico-rubral axonal projection increase during rehabilitation (Ishida et al., 2016).

Looking forward to potential neurodiagnostic or neurotherapeutic applications, rapidly adapting and widespread networks such as those activated by the stimulus array in this study, could present an ideal target for monitoring or inducing plasticity and neural circuit reorganization in damaged systems (Brown et al., 2009; Frostig et al., 2012; Wardman et al., 2014; Johnson and Frostig 2015; Song et al., 2015). Neurological events that disrupt functional connectivity such as stroke, traumatic insult or disease-related degeneration can have a profound effect on sensory and sensorimotor processing. During acute injury, some regions of the brain sustain immediate hypovolemic damage, while other areas can remain viable and capable of plastic reorganization due to collateral blood flow through pre-existing microcirculation anastomoses. It is this collateral microcirculation that seems to be key 
to minimizing acute damage and offset adverse outcomes throughout the prolonged period of recovery, and may be accessed by stimulation paradigms like those presented here (Shuaib et al., 2011; Lay et al., 2011, 2012; Liebeskind, 2012; Lay and Frostig, 2014). Similarly, chronic sensorimotor recovery is highly dependent on both the activation of existing connections, and the development of new connections either through sensory, motor or combined stimulation (Moskowitz et al., 2010, Nudo and McNeal, 2013).

It follows that a future course of action to bolster recovery may be to combine classic motor therapies, well-timed pharmacological support and sensory stimulation to augment beneficial outcomes in human sensorimotor rehabilitation. Either as an adjunct to concurrent physical therapy and retraining, or as a select therapy for brain-injured survivors with limited mobility, dose specific, patterned sensory inputs could potentially improve long-term outcomes by boosting connectivity via these large areas of activation (Farkas et al., 1999; Small et al., 2002; Luft et al., 2005; Farias da Guarda and Conforto, 2014).

\section{Experimental procedures}

\subsection{Participants}

Participants included 20 neurotypical adults (15 females), aged 18-30 (mean age $=22.3$ years, SD $=1.7$ ), and right-hand dominant per selfreport. All participants had no history of chronic illness or scheduled medications, and each was consented in accordance with the university institutional review board approval (includes The Code of Ethics of the World Medical Association-Declaration of Helsinki).

\subsection{Study design}

Five stimulus conditions $(5 \mathrm{~cm} / \mathrm{s}, 25 \mathrm{~cm} / \mathrm{s}, 65 \mathrm{~cm} / \mathrm{s}$, 'ALL-ON,' and 'ALLOFF') were presented in a randomized-balanced block design (Fig. 6). Randomization was used to address the differences in number of stimuli that could be delivered in each velocity condition (fewer pulses at the $5 \mathrm{~cm} / \mathrm{s}$ velocity versus more pulses at the $65 \mathrm{~cm} / \mathrm{s}$ velocity). The three velocity trains were randomly combined with an 'ALL-ON' condi- 
tion (tactile stimulator cells activated simultaneously at $1 \mathrm{~Hz}$, without the velocity variable) and an 'ALL-OFF' condition (pneumatic input to TAC-Cells switched off) to allow for statistical comparison of the effect of each velocity, and the main effect of velocity alone.

\subsection{Scanning protocol}

Neuroimaging was performed using a 3T Siemens Skyra MRI scanner fitted with a 32-channel receiving head coil. A single imaging session consisted of an anatomical scan (T1-weighted MPRAGE, $0.9 \mathrm{~mm}$ isotropic, TE $=3.37 \mathrm{~ms}, \mathrm{TR}=2400 \mathrm{~ms}$ ) lasting approximately $6 \mathrm{~min}$, followed by three functional (BOLD) data sets lasting 13.3 min each. The functional image (T2/-weighted EPI) brain volumes consisted of 41 interleaved slices ( $2.5 \_2.5 \_2.5 \mathrm{~mm}^{3}, \mathrm{TE}=30 \mathrm{~ms}$, TR $\left.=2500 \mathrm{~ms}\right)$ with a $220 \mathrm{~mm}$ field of view oriented to include orofacial sensorimotor cortex and cerebellum.

Each of the 3 BOLD acquisition sessions consisted of 5 stimulus conditions repeated 4 times in counterbalanced order to yield a total of 20 blocks. Each block was $40 \mathrm{~s}$ in length with the first $20 \mathrm{~s}$ dedicated to the repeated presentation of one of the five possible stimulus conditions $(5 \mathrm{~cm} / \mathrm{s}, 25 \mathrm{~cm} / \mathrm{s}, 65 \mathrm{~cm} / \mathrm{s}$, ALL-ON simultaneous activation, ALL-OFF), followed by $20 \mathrm{~s}$ of quiescence to allow for hemodynamic response decay and neurocapillary recovery. Thus, with a TR $=2.5 \mathrm{~s}$, each block resulted in 16 volumes acquired (Fig. 6). The full BOLD session totaled $800 \mathrm{~s}$ yielding 320 sampled volumes. The full scan time averaged about 46 min per participant (MPRAGE +3 BOLDs).

\subsection{Stimulus device: TAC-Cell array}

Pneumotactile velocity stimuli (Fig. 5) were delivered to the facial skin by a multichannel pneumatic amplifier (GALILEO Somatosensory ${ }^{\top M}$, Epic Medical Concepts \& Innovations, Shawnee Mission, KS USA), which was programmed to generate biphasic pulses [duration $=60$ $\mathrm{ms}, 10 \mathrm{~ms}$ rise-fall time (10-90\% intercepts), amplitude from -5 to 28 $\mathrm{kPa}$, (Fig. 5.a). A PC laptop computer (MS WIN8.1 $\times 64$ bit) ran the graphical user interface to control the GALILEO via a USB port for sequential activation of output channels 1 through 5 with an XML-coded saltatory velocity program individualized to each participant based on their perioral morphometrics. Pneumatic TAC-Cells were aligned on 

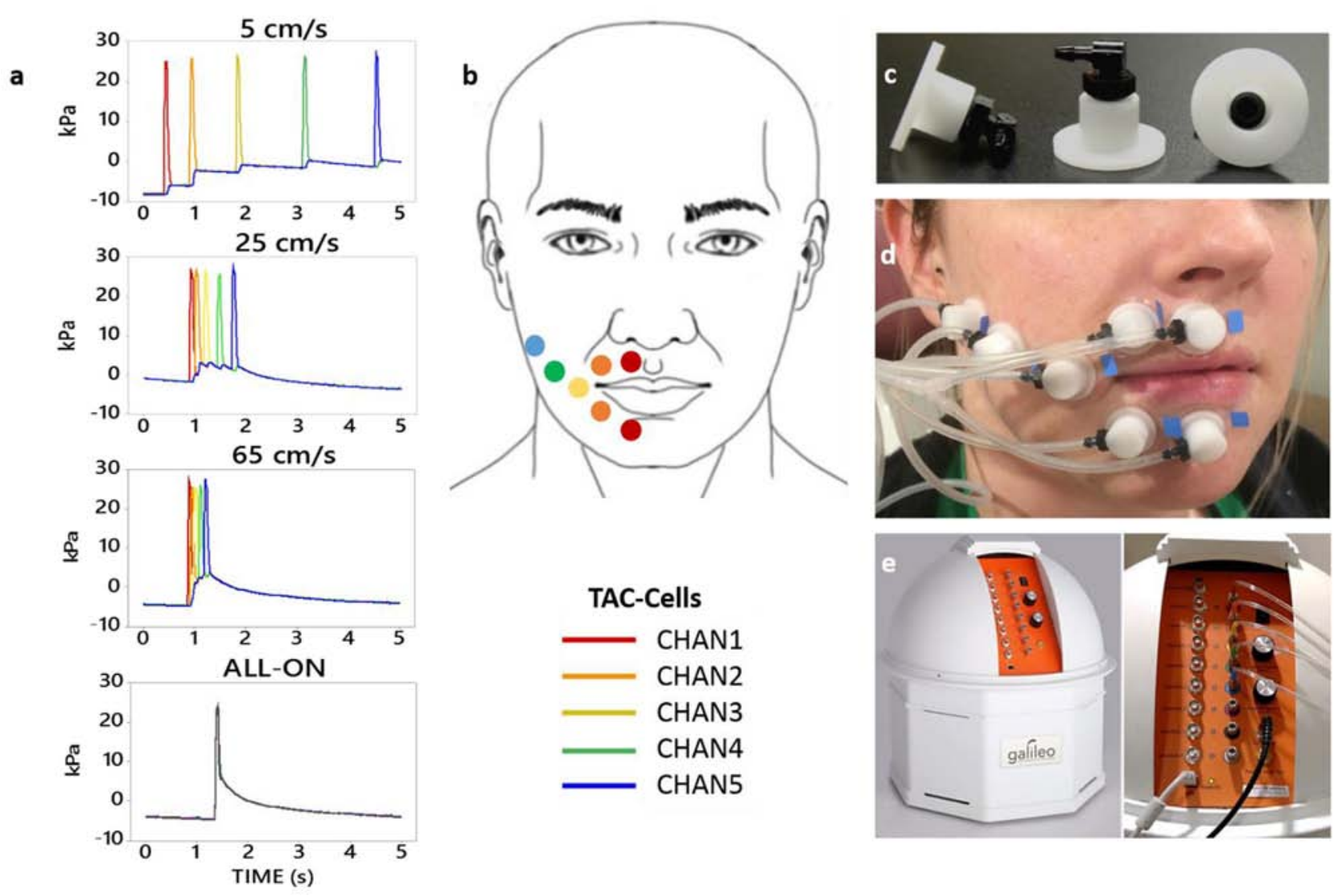

Fig. 5. The GALILEO Somatosensory Stimulator with Pneumatic Velocity Array Configuration. Programmed time delays (a) between pressure pulses at each TAC-Cell resulted in 5 stimulus conditions: $5 \mathrm{~cm} / \mathrm{s}, 25 \mathrm{~cm} / \mathrm{s}, 65 \mathrm{~cm} / \mathrm{s}$, ALL-ON synchronous activation $(1 \mathrm{~Hz}$ ), and ALL-OFF (not shown as pressure waveform would be flat, no output). Pneumatic cells (b) were aligned on the participant from the right philtral column to the right (buccal) face. TAC-Cells shown (c), white flanged surface was adhered to skin surface with double adhesive collars. A series of pneumotactile 'saltatory' stimuli (d) traversed the skin in a repeating medial-to-lateral direction at three velocities $(5,25,65 \mathrm{~cm} / \mathrm{s})$ as well as the 'ALL-ON' and 'ALL-OFF' control conditions. Note channels 1 and 2 (joined with bifurcated tubing) stimulate both the upper and lower perioral areas simultaneously. The GALILEO somatosensory stimulator (e).

the participant from the right philtral column to the right (buccal) face (Fig. 5.b, d). Once in place, the array traverse length was calculated based on the distance between cells (each length measured from the center of one cell to center of the next). Because of bifurcation of the first two channels, both the upper and lower cells of those channels were considered 'first' and 'second' in the array. The measurement 


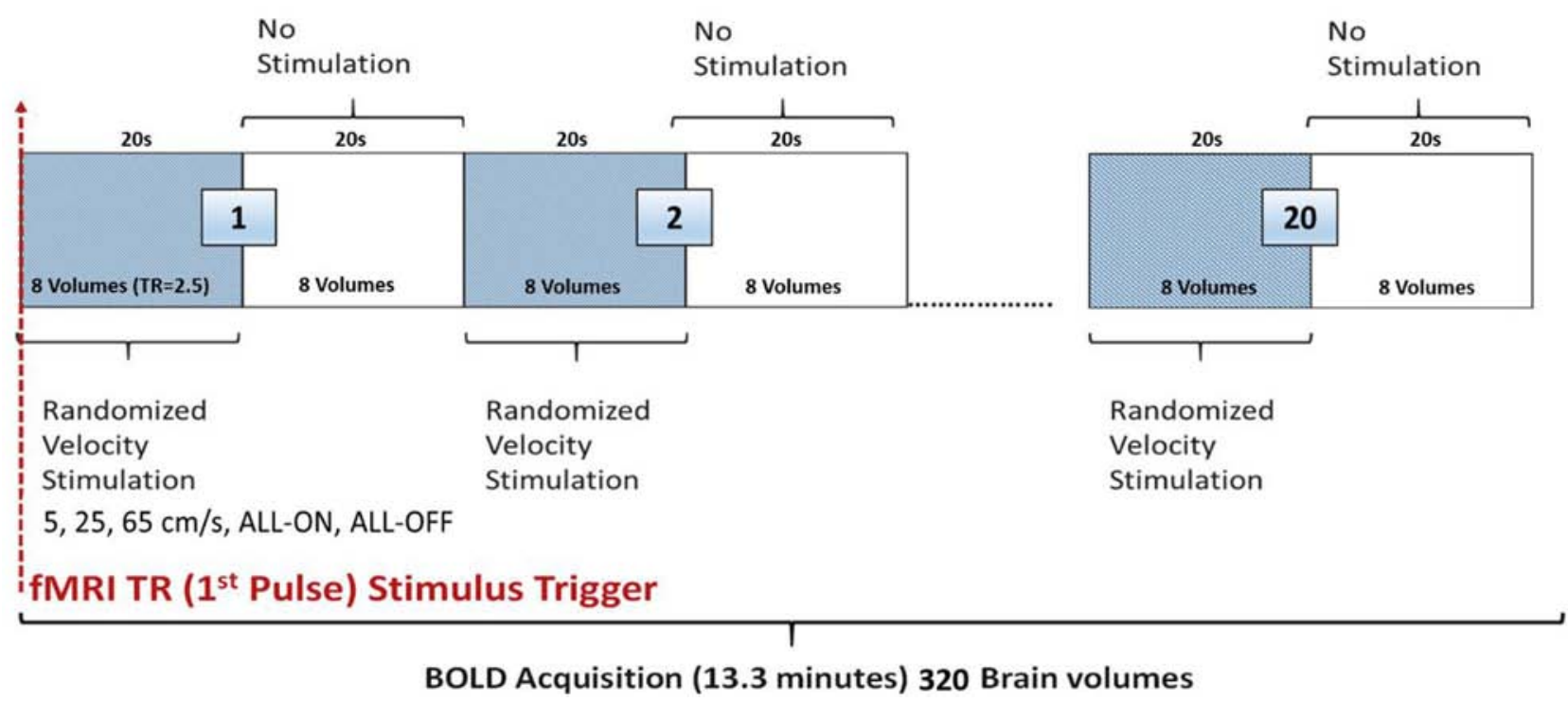

Fig. 6. Randomized Block Design for Stimulus Presentation and Scan Acquisition/ Co-Registration.

values of array length were used to designate on/off times for velocity sequences (traverse speed in $\mathrm{cm} / \mathrm{s}$ ). Thus, velocity protocols were consistent across all participants, regardless of orofacial size. The resulting program produced a series of pneumotactile 'saltatory' stimuli that traversed the skin in a repeating medial-to-lateral (upper/lower lips to lateral cheek) direction at three velocities $(5,25,65 \mathrm{~cm} / \mathrm{s})$ as well as the 'ALL-ON' and 'ALL-OFF' control conditions.

The stimulation array consisted of 7 small, open-chambered pneumatic capsules known as TAC-Cells that were adhered to the hairy skin of the right lower face, effectively sealing it to the skin. In this way, pressure dynamics within each cell resulted in skin deflection without acoustic or electrical artifact. Participants reported the resulting sensory experience as a moving sequence of discrete 'taps' or 'raindrops' on their lower face. These TAC-Cells are machined from Delrin ${ }^{\circledR}$ acetal thermoplastic ( $6 \mathrm{~mm} \mathrm{ID,} 15 \mathrm{~mm} \mathrm{OD}, 6 \mathrm{~mm} \mathrm{H})$ which are ported through a barb-fitting and connected to a $25 \mathrm{~cm}$ length of silicone tubing for flexible strain relief, and then coupled to a $5.18 \mathrm{~m}(1.6 \mathrm{~mm}$ ID) polyurethane line attached to the designated pneumatic ports on the GALILEO stimulus generator (Fig. 5.d, e). The flanged surface of each TAC-Cell was secured to the skin using double-adhesive tape collars following skin preparation with tincture of benzoin to improve adhesion (Fig. 5.c, d). 


\section{5. fMRI data acquisition and stimulus co-registration}

Pneumotactile stimulus generation was synchronized to the Siemens scanner using the first optical output TR (repetition time) TTL (transistor-transistor logic) pulse (Fig. 6). The first TR pulse from the scanner at the onset of each BOLD acquisition was input to a Berkeley Nucleonics (Model 645) programmable pulse generator connected to the GALILEO stimulator. The pulse generator served as a timing mechanism via external trigger to accurately cue the GALILEO stimulator to produce a programmed velocity sequence every $40 \mathrm{~s}$. Thus, the GALILEO would present a velocity condition for $20 \mathrm{~s}$, then wait for the external trigger to initiate the next random velocity sequence at $40 \mathrm{~s}$, providing the 20 -s quiescent period between velocity blocks.

\subsection{Data analysis}

\subsection{1. fMRI preprocessing}

Analysis of the fMRI data was conducted using a general linear model (GLM) in Statistical Parametric Mapping (SPM12) software (Wellcome Trust Centre for Neuroimaging, University College London, UK), to examine regions of cortical and subcortical activation associated with the main effect of velocity, and the effect of each velocity compared to the two control conditions (ALL-OFF, ALLON). Images were pre-processed [motion corrected, co-registered with the anatomical MPRAGE, segmented by tissue type, normalized to Montreal Neurological Institute (MNI) space, and smoothed using an isotropic Gaussian kernel $(\mathrm{FWHM}=8 \mathrm{~mm})]$. Once preprocessed, a design matrix was created for assessment with GLM.

\subsubsection{Single subject analysis matrix}

First-level specification in SPM (single-subject) was used to build a matrix containing five predictor conditions $(5 \mathrm{~cm} / \mathrm{s}, 25 \mathrm{~cm} / \mathrm{s}, 65 \mathrm{~cm} / \mathrm{s}$, ALL-OFF, ALL-ON) with six motion correction regressors (translational axes $X, Y, Z$, roll, pitch, yaw) in each subjects' single (320 vol) session. All volumes were realigned to the first volume in each session, and a box-car method was used to create the analysis matrix for the initial single-subject processing stream, where a value of ' 10 at a set 
time point modeled a condition of 'velocity,' with ' 00 at all other time points. Time points for the velocity conditions were obtained from the GALILEO output files recorded during each subject's data collection. Next, the three BOLD data acquisition sessions for each participant were pooled using the FFX (fixed effects, group modeling) estimate function to create a matrix of all participants' data for each condition. In subsequent group analyses (second-level), the 'ALL-OFF' or 'ALL$\mathrm{ON}^{\prime}$ conditions were used as the comparative baseline for individual velocity $(5,25,65 \mathrm{~cm} / \mathrm{s})$ estimates. Note that for two participants, one single session BOLD data was unusable, resulting in 58 BOLD sessions rather than 60 for analysis.

\subsubsection{Group analysis matrix}

For second-level (group) analysis, a one-way ANOVA within-subjects design $[F(2,38)=11.85, p<0.001$, uncorrected, minimum extent 10 voxels], was used to estimate the overall main effect of velocity (5 $\mathrm{cm} / \mathrm{s}, 25 \mathrm{~cm} / \mathrm{s}, 65 \mathrm{~cm} / \mathrm{s}$ ) across the 20 participants (Table 1). A whole brain slice montage of ANOVA (main effect) data was created with MATLAB (v17) bspmview toolbox (Spunt, 2016) showing sagittal and coronal views of activation (Fig. 1). Key positive activation peaks associated with main effect clusters were labeled according to probabilistic cytoarchitectonic maps (Eickhoff et al., 2005) using SPM Anatomy toolbox (Table 1). Of those, six activation clusters (Table 1, highlighted) were selected for region of interest (ROI) analysis of putative facial sensorimotor velocity processing networks based on findings from related literature (Ito and Gomi, 2007; Lin et al., 2010; Grabski et al., 2012; Todd, 2012; Kedarnath and Shruthi, 2015; Rocchi et al., 2016).

\subsubsection{Velocities > control conditions}

Pooled group data was also assessed to evaluate BOLD activation associated with individual velocities compared to control conditions. One-sample t-tests $[\mathrm{t}(19)=3.58, \mathrm{p}<0.001$, uncorrected, minimum extent 10 voxels] were used to create six additional contrasts which included; $5 \mathrm{~cm} / \mathrm{s}>$ ALL-OFF, $25 \mathrm{~cm} / \mathrm{s}>$ ALL-OFF, $65 \mathrm{~cm} / \mathrm{s}>$ ALL-OFF (Table 2), and $5 \mathrm{~cm} / \mathrm{s}>$ ALL-ON, $25 \mathrm{~cm} / \mathrm{s}>$ ALLON, $65 \mathrm{~cm} / \mathrm{s}>$ ALL-ON (Table 3). Positive one-sample $t$-test cluster activations were rendered on an inflated surface (20 mm peak separation), (Figs. 2.1, 3.1), and us- 
ing a whole brain slice montage showing deep cerebral and cerebellar regions of activation (Figs. 2.2, 3.2), (MATLAB bspmview).

\subsection{5. $R O I$ analysis}

Main effect data from 20 participants was assessed at MNI coordinates pertaining to the 6 ROls of putative facial somatosensory velocity processing networks. Estimates of \%BOLD signal change by condition $(5 \mathrm{~cm} / \mathrm{s}>$ ALL-OFF, $5 \mathrm{~cm} / \mathrm{s}>$ ALL-ON, $25 \mathrm{~cm} / \mathrm{s}>$ ALLOFF, $25 \mathrm{~cm} / \mathrm{s}>$ ALL-ON, $65 \mathrm{~cm} / \mathrm{s}>$ ALL-OFF, $65 \mathrm{~cm} / \mathrm{s}>$ ALL-ON) in each ROI were obtained using the mean response (group analysis) function in SPM Anatomy toolbox (calculated by dividing the signal by the whole brain average). A post-hoc Tukey pairwise comparison ( $\mathrm{N}=58, \mathrm{p}<0.05, \mathrm{Cl}$ 0.95 ) was used to estimate differences in mean BOLD responses by velocity in each ROI (Figs. 4.1-4.6.b).

Fitted response estimates (SPM 12) of main effect ROI data plotted against scan/time were used to evaluate the BOLD time course of cluster maximas over a 40-s acquisition block (20 s stimulation/ 20 stimulation off). Main effect (ANOVA) data was used to create different experimental levels $(5,25,65 \mathrm{~cm} / \mathrm{s})$ of velocity for each $\mathrm{ROI}$ at specified MNI coordinates. The SPM data was then matched to GALILEO output files to create the BOLD time course graph by each velocity level > ALL-OFF condition $(5 \mathrm{~cm} / \mathrm{s}>$ ALLOFF, $25 \mathrm{~cm} / \mathrm{s}>$ ALL-OFF, 65 $\mathrm{cm} / \mathrm{s}>$ ALL-OFF) per ROI across 20 participants (Figs. 4.1-4.6.c).

Acknowledgments - Supported in part by the Barkley Trust (S. Barlow, PI).

\section{References}

Ackerley, R., Carlsson, I., Wester, H., Olausson, H., Backlund, Wasling H., 2014. Touch perceptions across skin sites: differences between sensitivity, direction discrimination and pleasantness. Front. Behav. Neurosci. 54 (8), 1-10.

Antal, A., Bikson, M., Datta, A., Lafon, B., Dechent, P., Parra, L.C., Paulus, W., 2014. Imaging artifacts induced by electrical stimulation during conventional fMRI of the brain. Neurolmage 15 (85), 1040-1047.

Aronoff, R., Ferenc, M., Mateo, C., Ciron, C., Schneider, B., Petersen, C.C.H., 2010. Long-range connectivity of mouse primary somatosensory barrel cortex. Eur. J. Neurosci. 31, 2221-2233. 
Barlow, S., 1987. Mechanical frequency detection thresholds in the human face. Exp. Neurol. 96 (2), 253-261.

Barlow, S., Bradford, P., 1996. Comparison of perioral reflex modulation in the upper and lower lip. J. Speech Hear. Res. 39, 55-75.

Barlow, S., 1998. Real time modulation of speech-orofacial motor performance by means of motion sense. J. Commun. Disord. 31 (6), 511-533.

Beauchamp, M., Pasalar, S., Ro, T., 2010. Neural substrates of reliability-weighted visual-tactile multisensory integration. Front. Syst. Neurosci. 4, 25.

Bensmaia, S., 2008. Tactile intensity and population codes. Behav. Brain Res. 190 (2), 165-173.

Blankenburg, F., Ruben, J., Meyer, R., Schwiemann, J., Villringer, A., 2003. Evidence for a rostral-to-caudal somatotopic organization in human primary somatosensory cortex with mirror-reversal in areas $3 \mathrm{~b}$ and 1. Cereb. Cortex 13, 987-993.

Blatow, M., Nennig, E., Durst, A., Sartor, K., Stippich, C., 2007. fMRI reflects functional connectivity of human somatosensory cortex. Neuroimage 37, 927-936.

Briggs, R., Dy-Liacco, I., Malcolm, M., Lee, H., Peck, K., Gopinath, K., et al., 2004. A pneumatic vibrotactile stimulation device for fMRI. Magn. Reson. Med. 51, 640-643.

Brown, C., Aminoltejari, K., Erb, H., Winship, I., Murphy, T., 2009. In vivo voltagesensitive dye imaging in adult mice reveals that somatosensory maps lost to stroke are replaced over weeks by new structural and functional circuits with prolonged modes of activation within both the peri-infarct zone and distant sites. J. Neurosci. 29, 1719-1734.

Capra, N., Dessem, D., 1992. Central connections of trigeminal primary afferent neurons: topographical and functional considerations. Crit. Rev. Oral Biol. Med. 4, 1-52.

Chen, C., Kreutz-Delgado, K., Sereno, M., Huang, R., 2017. Validation of periodic fMRI signals in response to wearable tactile stimulation. Neuroimage 15 (150), 99-111.

Chen, L., Friedman, R., Roe, A., 2003. Optical imaging of a tactile illusion in area $3 \mathrm{~b}$ of the primary somatosensory cortex. Science 302 (5646), 881-885.

Corbetta, M., Patel, G., Shulman, G., 2008. The reorienting system of the human brain: from environment to theory of mind. Neuron 58, 306-324.

Custead, R., Oh, H., Barlow, S., 2015. Adaptation of the cortical somatosensory evoked potential following pulsed pneumatic stimulation of the lower face in adults. Brain Res. 1622, 81-90.

Darian-Smith, I., Goodwin, A., Sugitani, M., Heywood, J., 1984. The tangible features of textured surfaces: their representation in the monkey's somatosensory cortex. Wiley, New York, pp. 475-500.

DaSilva, A., Becerra, L., Makris, N., Strassman, A.M., Gonzalez, R., Geatrakis, N., Borsook, D., 2002. Somatotopic activation in the human trigeminal pain pathway. J. Neurosci. 22 (18), 8183-8192. 
Dépeault, A., Meftah, E., Chapman, C., 2013. Neuronal correlates of tactile speed in primary somatosensory cortex. J. Neurophysiol. 110, 1554-1566.

Dileep, G., Hawkins, J., 2009. Towards a mathematical theory of cortical microcircuits. PLOS Comput. Biol. https://doi.org/10.1371/journal.pcbi.1000532

Downar, J., Crawley, A., Mikulis, D., Davis, K., 2000. A multimodal cortical network for the detection of changes in the sensory environment. Nat. Neurosci. 3, 277-283.

Dresel, C., Parzinger, A., Rimpau, C., Zimmer, C., Ceballos-Baumann, A., Haslingera, B., 2008. A new device for tactile stimulation during fMRI. Neurolmage 39, 1094-1103.

Dreyer, D., Hollins, A., Whitsel, B., 1978. Factors influencing cutaneous directional sensitivity. Sensory Processes 2, 71-79.

Dubner, R., Sessle, B., Storey, A., 1978. The Neural Basis of Oral and Facial Function. Plenum Press, New York. 483 pages.

Eickhoff, S., Stephan, K., Mohlberg, H., Grefkes, C., Fink, G., Amunts, K., 2005. Zilles $\mathrm{K}$ A new SPM toolbox for combining probabilistic cytoarchitectonic maps and functional imaging data. Neurolmage 25, 1325-1335.

Edin, B., Essick, G., Trulsson, M., Olsson, K., 1995. Receptor encoding of moving tactile stimuli in humans. I. Temporal pattern of discharge of individual lowthreshold mechanoreceptors. J. Neurosci. 15 (1), 830-847.

Eickhoff, S., Grefkes, C., Fink, G., Zilles, K., 2008. Functional lateralization of face, hand, and trunk representation in anatomically defined human somatosensory areas. Cereb. Cortex 18, 2829-2830.

Essick, G., Afferica, T., Aldershof, B., Nestor, J., Kelly, D., Whitsel, B., 1988a. Human Perioral direction sensitivity. Exp. Neurol. 100, 506-523.

Essick, G., Bredehoeft, K., McLaughlin, D., Szaniszlo, 1991. Directional sensitivity along the upper limb. Somatosens. Mot. Res. 8 (1), 13-22.

Essick, G., 1998. Factors affecting direction discrimination of moving tactile stimulation. Adv. Psychol.-Amsterdam 127, 1-54.

Essick, G., Franzen, O., Whitsel, B., 1988b. Discrimination and scaling of velocity stimulus motion across the skin. Sens. Motor Res. 6 (1), 21-40.

Essick, G., McGuire, M., Joseph, A., Franzen, O., 1992. Characterization of the percepts evoked by discontinuous motion over the perioral skin. Somatosensory Motor Res. 2 (9), 175-184.

Estep, M., Barlow, S., 2007. Modulation of the trigeminofacial pathway during speech. Brain Res. 1171, 67-74.

Farias da Guarda, S., Conforto, A., 2014. Effects of somatosensory stimulation on corticomotor excitability in patients with unilateral cerebellar infarcts and healthy subjects - preliminary results. Cerebellum Ataxias 5 (1), 16.

Farkas, T., Kis, Z., Toldi, J., Wolff, J., 1999. Activation of the primary motor cortex by somatosensory stimulation in adult rats is mediated mainly by associational connections from the somatosensory cortex. Neuroscience 90, 353-361.

Ferezou, I., Haiss, F., Gentet, L., Aronoff, R., Weber, B., Petersen, C., 2007. Spatiotemporal dynamics of cortical sensorimotor integration in behaving mice. Neuron 56, 907-923. 
Favorov, O., Diamond, M., 1990. Demonstration of discrete place-defined columns segregates in the cat SI. J. Comp. Neurol. 298, 97-112.

Frostig, R., Lay, C., Davis, M., 2012. A rat's whiskers point the way toward a novel stimulus-dependent, protective stroke therapy. Neuroscientist 19 (3), 313-328.

Gao, J., Parsons, L., Bower, J., Xiong, J., Li, J., Fox, P., 1996. Cerebellum implicated in sensory acquisition and discrimination rather than motor control. Science 272 (5261), 545-547.

Geldard, F., Sherrick, C., 1972. The cutaneous "rabbit": a perceptual illusion. Science 178, 178-179.

Goldreich, D., Tong, J., 2013. Prediction, postdiction, and perceptual length contraction: A Bayesian low-speed prior captures the cutaneous rabbit and related illusions. Front. Psychol. 4, 221.

Goldreich, D., 2007. A Bayesian perceptual model replicates the cutaneous rabbit and other tactile spatiotemporal illusions. PLoS One 2 (3), e333.

Grabski, K., Lamalle, L., Vilain, C., Schwartz, J., Vallée, N., Tropres, I., Baciu, M., Le Bas, J., Sato, M., 2012. Functional MRI assessment of orofacial articulators: neural correlates of lip, jaw, larynx, and tongue movements. Hum. Brain Mapp. 33, 2306-2321.

Gruber, P., Gould, D., 2010. The red nucleus: past, present and future. Neuroanatomy 9, 1-3.

Halata, Z., Munger, B., 1983. The sensory innervation of primate facial skin. II. Vermilion border and mucosal lip. Brain Res. 286 (1), 81-107.

Hamdy, S., Rothwell, J., Aziz, Q., Singh, K., Thompson, D., 1998. Long-term reorganization of human motor cortex driven by short-term sensory stimulation. Nat. Neurosci. 1 (1), 64-68.

$\mathrm{Hu}$, L., Zhang, Z., Hu, Y., 2012. A time-varying source connectivity approach to reveal human somatosensory information processing. Neurolmage $62,217-$ 228.

Huang, R., Chen, C., Tran, A., Holstein, K., Sereno, M., 2012. Mapping multisensory parietal face and body areas in humans. Proc. Natl. Acad. Sci. USA 109 (44), 18114-18119.

Huang, R., Sereno, M., 2007. Dodecapus: An MR-compatible system for somatosensory stimulation. Neuroimage 34 (3), 1060-1073.

Iannetti, G., Porro, C., Pantano, P., Romanelli, P., Galeotti, F., Cruccu, G., 2003. Representation of different trigeminal divisions within the primary and secondary human somatosensory cortex. Neurolmage 19, 906-912.

Igelstrom, K., Graziano, M., 2017. The inferior parietal lobule and temporoparietal junction: a network perspective In Press Neuropsychologia. In Press.

Indovina, I., Macaluso, E., 2007. Dissociation of stimulus relevance and saliency factors during shifts of visuospatial attention. Cerebral Cortex 17, 1701-1711.

Ishida, A., Isa, K., Umeda, T., Kobayashi, K., Kobayashi, K., Hida, H., Isa, T., 2016. Causal link between the cortico-rubral pathway and functional recovery through forced Impaired limb use in rats with stroke. J. Neurosci. 36 (2), 455467. 
Ito, T., Gomi, H., 2007. Cutaneous mechanoreceptors contribute to the generation of a cortical reflex in speech. Sensory Motor Syst. 18 (9), 907-910.

Iwamura, Y., Tanaka, M., Iriki, A., Taoka, M., Toda, T., 2002. Processing of tactile and kinesthetic signals from bilateral sides of the body in the postcentral gyrus of awake monkeys. Behav. Brain Res. 135, 185-190.

Jiang, Y., Zaaimi, B., Martin, J., 2016. Competition with primary sensory afferents drives remodeling of corticospinal axons in mature spinal motor circuits. J. Neurosci. 6 (36), 193-203.

Johansson, R., Trulsson, M., Olsson, K., Westberg, K., 1988. Mechanoreceptor activity from the human face and oral mucosa. Exp. Brain Res. 72 (1), 204-208.

Johnson, B., R. Frostig Long, intrinsic horizontal axons radiating through and beyond rat barrel cortex have spatial distributions similar to horizontal spreads of activity evoked by whisker stimulation. Brain Struct. Funct. 2015, epub ahead of print, PMID: 26438334.

Johnson, K., Lamb, G., 1981. Neural mechanisms of spatial tactile discrimination: neural patterns evoked by Braille-like dot patterns in the monkey. J. Physiol. 310, 117-144.

Jones, E., 1992. Anatomy of cerebral cortex: Columnar input-output organization. In: Schmitt, F.O. (Ed.), The Organization of the Cerebral Cortex. MIT Press, Cambridge, MA, pp. 199-235.

Kaelin-Lang, A., Luft, A., Sawaki, L., Burstein, A., Sohn, Y., Cohen, L., 2002. Modulation of human corticomotor excitability by somatosensory input. J. Physiol. 540, 623-633.

Kedarnath, N., Shruthi, R., 2015. MRI as an essential diagnostic approach for trigeminal neuralgia. J. Maxillof. Oral Surg. 14 (1), 462-464.

Kennedy, T., Grimm, R., Towe, A., 1966. The role of cerebral cortex in evoked somatosensory activity in cat cerebellum. Exp. Neurol. 14 (1), 13-23.

Kincade, J., Abrams, R., Astafiev, S., Shulman, G., Corbetta, M., 2005. An eventrelated functional magnetic resonance imaging study of voluntary and stimulus-driven orienting of attention. J. Neurosci. 25, 4593-4604.

Kitazawa, S., 2013 Aug. The science of the mental present: implications of temporal illusions. Brain Nerve 65 (8), 911-921.

Kohn, A., Whitsel, B., 2002. Sensory cortical dynamics. Behav. Brain Res. 135, 119-126.

Küper, M., Dimitrova, A., Thürling, M., Maderwald, S., Roths, J., Elles, H.G., Gizewski, Ladd, E.R., M.E., Diedrichsen, J., Timmann, D., 2011. Evidence for a motor and a non-motor domain in the human dentate nucleus-an fMRI study. Neurolmage 54 (4), 2612-2622.

Lamb, G., 1983. Tactile discrimination of textured surfaces: Psychophysical performance measurements in humans. Journal of Physiology 338, 551-565.

Lay, C., Davis, M., Chen-Bee, C., Frostig, R., 2011. Mild sensory stimulation reestablishes cortical function during the acute phase of ischemia. J. Neurosci. 31 (32), 11495-11504. 
Lay, C., Davis, M., Chen-Bee, C., Frostig, R., 2012. Mild sensory stimulation completely protects the adult rodent cortex from ischemic stroke. PLoS ONE 5 (6), e11270.

Lay, C., Frostig, R., 2014. Complete protection from impending stroke following permanent middle cerebral artery occlusion in awake, behaving rats. Eur. J. Neurosci. 40 (9), 3413-3421.

Liebeskind, D., 2012. Trials of endovascular therapies or collaterals? Int. J. Stroke 8, 258-259.

Lin, C., Sun, Y., Huang, C., Yu, C., Ju, M., 2010. Cortical activation by tactile stimulation to face and anterior neck areas: an fMRI study with three analytic methods. Hum. Brian Mapp. 31 (12), 1876-1885.

Lipworth, G., Ensworth, J., Seetharam, K., Lee, J., Schmalenberg, P., Nomura, T., Reynolds, M., Smith, D., Urzhumov, Y., 2015. Quasi-static magnetic field shielding using longitudinal mu-near-zero metamaterials. Sci. Rep. 3 (5), 12764. https://doi.org/10.1038/srep12764

Liu, Y., Pu, Y., Gao, J., Parsons, L., Xiong, J., Liotti, M., Bower, J., Fo, P., 2000. The human red nucleus and lateral cerebellum in supporting roles for sensory information processing. Hum. Brain Mapp. 10 (4), 147-159.

Luft, A., Manto, M., Ben, Taib N., 2005. Modulation of motor cortex excitability by sustained peripheral stimulation: the interaction between the motor cortex and the cerebellum. Cerebellum 4 (2), 90-96.

Luken, L., Evert, M., Wessberg, J., 2011. Pleasantness of touch in human glabrous and hairy skin: order effects on affective ratings. Brain Res. 1417, 9-15.

Lundblad, L., Olausson, H., Hermansson, A., Wasling, H., 2011. Cortical processing of tactile direction discrimination based on spatiotemporal cues in man. Neurosci. Lett. 50 (1), 45-49.

Macaluso, E., Frith, C., Driver, J., 2002. Supramodal effects of covert spatial orienting triggered by visual or tactile events. J. Cogn. Neurosci. 14 (3), 389401.

McGlone, F., Reilly, D., 2010. The cutaneous sensory system. Neurosci. Biobehav. Rev. 34 (2), 148-159.

Miyamoto, J., Honda, M., Saito, D., Okada, T., Ono, T., Ohyama, K., Sadato, N., 2005. The representation of the human oral area in the somatosensory cortex: $\mathrm{A}$ functional MRI study. Cereb. Cortex 16, 669-675.

Moskowitz, M., Lo, E., ladecola, C., 2010. The science of stroke: mechanisms in search of treatments. Neuron 67 (2), 181-198.

Mottolese, C., Richard, N., Harquel, S., Szathmari, A., Sirigu, A., Desmurget, M., 2013. Mapping motor representations in the human cerebellum. Brain 136 (1), 330-342.

Munger, B., Halata, Z., 1983. The sensory innervation of primate facial skin I. Hairy skin. Brain Res. 286 (1), 45-80.

Nordin, M., Hagbarth, K., 1989. Mechanoreceptive units in the human infra-orbital nerve. Acta Physiol. Scand. 135 (2), 149-161.

Nudo, R., McNeal, D., 2013. Plasticity of cerebral functions. Handbook Clin. Neurol. 110, 13-21. 
Ohmae, S., Uematsu, A., Tanaka, M., 2013. Temporally specific sensory signals for the detection of stimulus omission in the primate deep cerebellar nuclei. J. Neurosci. 33 (39), 15432-15441.

Parsons, L., Bower, J., Gao, J., Xiong, J., Li, J., Fox, P., 1997. Lateral cerebellar hemispheres actively support sensory acquisition and discrimination rather than motor control. Learn. Memory 4 (1), 49-62.

Pei, Y., Bensmaia, S., 2014. The neural basis of tactile motion perception. J. Neurophysiol. 112 (12), 3023-3032.

Peron, S., Freeman, J., lyer, V., Guo, C., Svoboda, K., 2015. A cellular resolution map of barrel cortex activity during tactile behavior. Neuron 86 (3), 783-799. Phillips, J., Johnson, K., 1985. Neural mechanisms of scanned and stationary touch. J. Acoust. Soc. Am. 77 (1), 220-224.

Popescu, E., Barlow, S., Venkatesan, L., Wang, J., 2013. Popescu M. Adaptive changes in the neuromagnetic response of the primary and association somatosensory areas following repetitive tactile hand stimulation in humans. Hum. Brain Mapp. 34 (6), 1415-1426.

Popescu, M., Barlow, S., Popescu, M., Estep, M., Popescu, E.-A., Venkatesan, L., Auer, E., Brooks, W., 2010. Cutaneous stimulation of the digits and lips evokes responses with different adaptation patterns in primary somatosensory cortex. Neurolmage 52, 1477-1486.

Rocchi, L., Casula, E., Tocco, P., Berardelli, A., Rothwell, J., 2016. Somatosensory temporal discrimination threshold involves inhibitory mechanisms in the primary somatosensory area. J. Neurosci. 36 (2), 325-335.

Rowland, N., Jaeger, D., 2008. Responses to tactile stimulation in deep cerebellar nucleus neurons result from recurrent activation in multiple pathways. J. Neurophysiol. 99 (2), 704-717.

Rowe, M., Ferrington, D., Fisher, G., Freeman, B., 1985. Parallel processing and distributed coding for tactile vibratory information within sensory cortex. In:

Rowe, M.J., Willis, W.D. (Eds.), Development, Organization, and Processing In Somatosensory Pathways. Alan R. Liss Inc., New York, pp. 247-258.

Sato, M., Vilain, C., Lamalle, L., Grabski, K., 2015. Adaptive coding of orofacial and speech actions in motor and somatosensory spaces with and without overt motor behavior. J. Cogn. Neurosci. 27 (2), 334-351.

Schnepel, P., A. Kumar, M. Zohar, A. Aertsen, C. Boucsein, 2014. Physiology and impact of horizontal connections in rat neocortex. Cerebral Cortex, 25 (10), 3818-35.

Sereno, M., Huang, R., 2014. Multisensory maps in parietal cortex. Curr. Opin. Neurobiol. 24 (1), 39-46.

Servos, P., Engel, S., Gati, J., Menon, R., 1999. fMRI evidence for an inverted face representation in human somatosensory cortex. NeuroReport 10, 1393-1395.

Shuaib, A., Butcher, K., Mohammad, A., Saqqur, M., Liebeskind, D., 2011. Collateral blood vessels in acute ischemic stroke: a potential therapeutic target. Lancet Neurol. 10, 909-921. 
Small, S., Hlustik, P., Noll, D., Genovese, C., Solodkin, A., 2002. Cerebellar hemispheric activation ipsilateral to the paretic hand correlates with functional recovery after stroke. Brain 125 (7), 1544-1557.

Song, W., Truong, D., Bikson, M., Martin, J., 2015. Transspinal direct current stimulation immediately modifies motor cortex sensorimotor maps. J. Neurophysiol. 113 (7), 2801-2811.

Spunt, R., 2016. BSPMVIEW v.20161108 [MATLAB Data set 2016]. Zenodo. http:// doi.org/10.5281/zenodo.168074

Strick, P., Dum, R., Fiez, J., 2009. Cerebellum and nonmotor function. Annu. Rev. Neurosci. 32, 413-434.

Szaniszlo, J., Essick, G., Kelly, D., Joseph, A., Bredehoeft, 1998. Evocation and characterization of percepts of apparent motion on the face. Percept. Psychophys. 60 (5), 785-804.

Todd, G., 2012. Anisotropy and spatial acuity on human lips. Clin. Neurophysiol. 123 (8), 1593-1598.

Tomita, A., Kato, T., Sato, F., Hague, T., Oka, A., Yamamoto, M., Ono, T., Maeda, Y., Sessle, B., Yoshida, A., 2012. Somatotopic direct projections from orofacial areas of primary somatosensory cortex to pons and medulla, especially to trigeminal sensory nuclear complex, in rats. Neuroscience 200 (3), 166-185.

Tommerdahl, M., Favorov, O., Whitsel, B., 2010. Dynamic representations of the somatosensory cortex. Neurosci. Biobehav. Rev. 34, 160-170.

Tommerdahl, M., Simons, S., Chiu, J., Favorov, O., Whitsel, B., 2006. Ipsilateral input modifies the primary somatosensory cortex response to contralateral skin flutter. J. Neurosci. 26, 5970-5977.

Tommerdahl, M., Simons, S., Chiu, J., Favorov, O., Whitsel, B., 2005. Response of SI cortex to ipsilateral, contralateral and bilateral flutter stimulation in the cat. BMC Neuroscience 6, 29.

Trulsson, M., Francis, S., Kelly, E., Westling, G., Bowtell, R., McGlone, F., 2000. Cortical responses to single mechanoreceptive afferent microstimulation revealed with fMRI. Neurolmage 13, 613-622.

Trulsson, M., Johansson, R., 2002. Orofacial mechanoreceptors in humans: encoding characteristics and responses during natural orofacial behaviors. Behav. Brain Res. 135.

Venkatesan, L., Barlow, S., Popescu, M., Popescu, A., 2014. Integrating approach for studying adaptation mechanisms in the human somatosensory cortical network. Exp. Brain Res. 232, 3545-3554.

Venkatesan, L., Barlow, S., Popescu, M., Popescu, A., Auer, E., 2010. TAC-Cell inputs to human hand and lip induce short-term adaptation of the primary somatosensory cortex. Brain Res. 1348, 63-70.

Vossel, S., Weidner, R., Driver, J., Friston, K., Fink, G., 2012. Deconstructing the architecture of dorsal and ventral attention systems with dynamic causal modeling. J. Neurosci. 32, 10637-10648.

Wacker, E., Spitzer, B., Lützkendorf, R., Bernarding, J., Blankenburg, F., 2011. Tactile motion and pattern processing assessed with high-field fMRI. PLoS One 6 (9), e24860. 
Wardman, D., Gandevia, S., Colebatch, J., 2014. Cerebral, subcortical, and cerebellar activation evoked by selective stimulation of muscle and cutaneous afferents: an fMRI study. Physiol. Rep. 2 (4), e00270.

Warren, J., Santello, M., Helms, Tillery S., 2011 Mar 25. Effects of fusion between tactile and proprioceptive inputs on tactile perception. PLoS One 6 (3), e18073.

Welker, W., Comparative Study of Cerebellar Somatosensory Representations the Importance of Micromapping and Natural Stimulation. In: Glickstein M., Yeo C., Stein J. (eds) Cerebellum and Neuronal Plasticity 1987, NATO ASI Series (Series A: Life Sciences), vol 148. Springer, Boston, MA.

Whitsel, B., Favorov, O., Delemos, K., Tommerdahl, M., Essick, G., Nakhle, B., 1999. SI neuron response variability is stimulus tuned and NMDA receptor dependent. J. Neurophysiol. 81, 2988-3006.

Whitsel, B., Franzen, O., Dreyer, A., Hollins, M., Young, M., Essick, G., Wong, C., 1986. Dependence of subjective transverse length on velocity of moving tactile stimuli. Somatosensory Res. 3, 185-196.

Wu, C., Seo, H., Cohen, L., 2006. Influence of electric somatosensory stimulation on paretic-hand function in chronic stroke. Arch. Phys. Med. Rehabil. 87 (3), 351-357.

Zembrzycki, A., Chou, S., Ashery-Padan, R., Stoykova, A., O'Leary, D., 2013. Sensory cortex limits cortical maps and drives top-down plasticity in thalamocortical circuits. Nat. Neurosci. 16 (8), 1060-1067. 